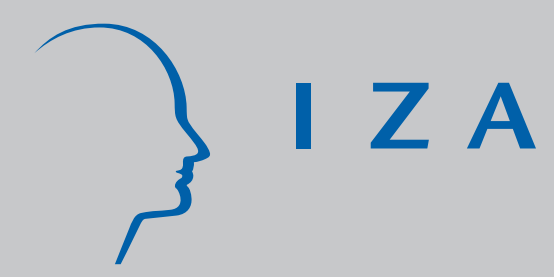

IZA DP No. 537

Unemployment Vouchers versus Low-Wage Subsidies

J. Michael Orszag

Dennis J. Snower

J uly 2002 


\title{
Unemployment Vouchers versus Low-Wage Subsidies
}

\author{
J. Michael Orszag \\ Watson Wyatt and IZA Bonn \\ Dennis J. Snower \\ Birkbeck College, University of London, \\ CEPR and IZA Bonn \\ Discussion Paper No. 537 \\ July 2002 \\ IZA \\ P.O. Box 7240 \\ D-53072 Bonn \\ Germany \\ Tel.: +49-228-3894-0 \\ Fax: +49-228-3894-210 \\ Email: iza@iza.org
}

This Discussion Paper is issued within the framework of IZA's research area Welfare State and Labor Market. Any opinions expressed here are those of the author(s) and not those of the institute. Research disseminated by IZA may include views on policy, but the institute itself takes no institutional policy positions.

The Institute for the Study of Labor (IZA) in Bonn is a local and virtual international research center and a place of communication between science, politics and business. IZA is an independent, nonprofit limited liability company (Gesellschaft mit beschränkter Haftung) supported by the Deutsche Post AG. The center is associated with the University of Bonn and offers a stimulating research environment through its research networks, research support, and visitors and doctoral programs. IZA engages in (i) original and internationally competitive research in all fields of labor economics, (ii) development of policy concepts, and (iii) dissemination of research results and concepts to the interested public. The current research program deals with (1) mobility and flexibility of labor, (2) internationalization of labor markets, (3) welfare state and labor market, (4) labor markets in transition countries, (5) the future of labor, (6) evaluation of labor market policies and projects and (7) general labor economics.

IZA Discussion Papers often represent preliminary work and are circulated to encourage discussion. Citation of such a paper should account for its provisional character. A revised version may be available on the IZA website (www.iza.org) or directly from the author. 
IZA Discussion Paper No. 537

July 2002

\section{ABSTRACT}

\section{Unemployment Vouchers versus Low-Wage Subsidies}

The paper examines the relative effectiveness of two policy proposals in reducing unemployment and working poverty: unemployment vouchers and low-wage subsidies. The unemployment vouchers are targeted exclusively at the unemployed (especially the longterm unemployed) and are provided only for a limited period of time. The low-wage subsidies, on the other hand, are granted to all low-wage earners regardless of their employment history and are of limitless duration. Our analysis indicates that the relative effectiveness of the two policies depends on workers' prospective wage growth. The more upwardly mobile workers are (i.e. the more their wages rise with employment duration), the more effective will unemployment vouchers be relative to low-wage subsidies. Conversely, the greater the danger that workers come to be trapped in dead-end jobs with flat wage profiles, the more effective will low-wage subsidies be relative to unemployment vouchers.

JEL Classification: J23, J32, J38, J64, J65, J68

Keywords: $\quad$ unemployment, poverty, wages, employment, vouchers, subsidies, inequality

Dennis Snower

Department of Economics

Birkbeck College

University of London

7 Gresse Street

London W1P 1LL

UK

Tel.: +44 (207) 6316408

Fax: +44 (207) 6316416

Email: dsnower@economics.bbk.ac.uk 


\title{
UNEMPLOYMENT VOUCHERS VERSUS LOW-WAGE SUBSIDIES
}

\author{
J. MICHAEL ORSZAG AND DENNIS J. SNOWER
}

\section{INTRODUCTION}

In both Europe and the United States policy makers have been searching for new labor market measures that keep unemployment low and avoid large disparities in income. This paper examines two policy proposals that have this aim: (i) unemployment vouchers $^{1}$ and (ii) low-wage subsidies. ${ }^{2}$ The unemployment vouchers are targeted exclusively at the unemployed (especially the long-term unemployed) and are provided only for a limited period of time. The low-wage subsidies, on the other hand, are granted to all lowwage earners regardless of their employment history and are of limitless duration.

Naturally, the impact effects of unemployment vouchers and low-wage subsidies are quite different. Since unemployment vouchers are targeted typically at the long-term unemployed whereas low-wage subsidies are targeted at the low-wage employed, it may be tempting to think that the two policies address different government objectives, namely, that the unemployment vouchers fight unemployment while the low-wage subsidies combat working poverty. This impression is misleading, however. Both policies affect the incentives to work. ${ }^{3}$ Thus both policies influence both unemployment and working poverty.

The unemployment vouchers are meant to reduce unemployment and inequality by stimulating the employment of those who

\footnotetext{
Date: 30 November 2001 .

${ }^{1}$ See, for example, (Snower 1994) (Orszag and Snower 2000) (Snower 1996) (Orszag and Snower 1998) (Orszag and Snower 1999).

${ }^{2}$ The case for low-wage subsidies has been argued most elegantly in (Phelps 1997). See, furthermore, (Hoon and Phelps 1997)) and (Phelps 1996).

${ }^{3}$ They also have quite different effects on the incentives to acquire human capital; but this important topic lies beyond the scope of this paper.
} 
are currently long-term unemployed, while the low-wage subsidies pursue these dual objectives by promoting the employment of the working poor. Broadly speaking, the former promotes equity by reducing unemployment, while the latter reduces unemployment by promoting equity. ${ }^{4}$

The effectiveness of the policies in stimulating employment versus alleviating poverty depends on the degree to which their incidence falls on employers versus employees. If the major influence of the policies is to reduce the wages paid by employers, then they will do more to stimulate employment than to alleviate working poverty. On the other hand, if their major influence is to raise the wages of the target group, then they will have a greater effect on mitigating working poverty than stimulating employment. ${ }^{5}$

The big question is how large these relative influences are. Our analysis indicates that the relative effectiveness of the two policies depends on workers' prospective wage growth. The more upwardly mobile workers are (i.e. the more their wages rise with employment duration), the more effective will unemployment vouchers be relative to low-wage subsidies. Conversely, the greater the danger that workers come to be trapped in dead-end jobs with flat wage profiles, the more effective will low-wage subsidies be relative to unemployment vouchers.

The paper is organized as follows. Section 2 discusses the underlying ideas that drive the conclusions of our analysis. Section

\footnotetext{
${ }^{4}$ Both policy approaches share some important advantages. They both are potentially able to alleviate a wide variety of market failures that lead to excessive labor costs and thereby depress labor demand (such as the market failures highlighted in the adverse selection, moral hazard, insider-outsider, and union theories of labor market activity). Moreover, both are more flexible tools for reducing unemployment and stimulating employment than discretionary labor market policies, such as public sector employment or discretionary subsidies to groups of workers with particular characteristics.

${ }^{5}$ In practice, the policies may generally be expected to affect both the wages employers pay and those employees receive, and the relative magnitudes of these effects will depend on such factors as the relative bargaining strength of employers and employees, the elasticity of labor supply with respect to the policies, the effect of the policies on other welfare state entitlements, and the gap between employers' recruitment and retention rates.
} 


\section{UNEMPLOYMENT VOUCHERS VERSUS LOW-WAGE SUBSIDIES}

3 presents our model of labor market behavior. ${ }^{6}$ In Section 4, we analyze people's incentives to work. In Section 5 we solve a specific example of the model. In Section 6, we examine the effectiveness of given hiring subsidies and employment vouchers in this context. Section 7 discusses the optimal employment subsidy and show how this depends on the tenure structure of wages. Section 8 concludes.

\section{UNDERLYING IDEAS}

As our analysis will show concretely, an unemployed person's incentive to find work depends on the "penalty" for not finding a job. This penalty is the difference between the present value of becoming employed and the present value of remaining unemployed. Similarly, an employee's incentive to put effort into the job (in order to reduce the chances of losing the job) depends on the penalty of job loss, which is the difference between the present value of remaining employed and the present value of becoming unemployed.

In this context, low-wage subsidies - financed through payroll taxes on high-wage employees and through unemployment benefits foregone ${ }^{7}$ - has a straightforward influence on work incentives. Supposing that the high-wage employees are skilled whereas the low-wage employees are unskilled, the LWSs raise the present value of unskilled employment and, with it, the penalty for not finding and keeping an unskilled job. It also reduces the present value of skilled employment, thereby reducing the penalty for not finding

\footnotetext{
${ }^{6}$ The model draws its inspiration from a labor market model developed by ((Phelps 1994), ch. 15) which we have applied to the analysis of unemployment accounts in (Orszag and Snower 1997). Our innovations here include the incorporation of job search, extension to more than two states to incorporate duration effects of employment and unemployment, incorporation of targetting of employment subsidies, development of the production side of the model and analysis of policies which satisfy a government budget constraint and/or an inequality constraint.

${ }^{7}$ These are unemployment benefits that do not have to be paid for unemployed people who find jobs.
} 
and keeping a skilled job. The overall influence on employment is ambiguous. $^{8}$

By contrast, unemployment vouchers - financed through payroll taxes on current employees and through the unemployment benefits foregone - have a different sequence of intertemporal effects. Suppose that the vouchers are targeted at people who have previously been long-term unemployed and are received in the first few periods of employment. Then the UVs raise the present value of long-term unemployment (that qualifies people for the vouchers) and of short-term employment (when the voucher payments accrue), but, if payroll taxes rise to finance vouchers, this will reduce the present value of long-term employment. Thus the vouchers raise the long-term unemployed people's penalty for not finding jobs, raise the short-term employed people's penalty for job loss, but they may reduce the corresponding penalty for the long-term employed people. Once again, the overall influence on employment is ambiguous. ${ }^{9}$

Thus the question is not whether LWSs and UVs can always guarantee more employment - they can't - but under what circumstances they are effective and on what their relative impact depends. Our analysis indicates that a particularly important phenomenon in this respect is the prospective rate of wage growth.

The greater the growth rate of an individual's real wage with respect to job tenure, the more effective UVs become relative to LWSs. The reason is straightforward. The greater the rate of real wage growth, the greater is the employee's incentive to work hard so as to avoid job loss, and the less the UVs reduce the employee's penalty from job loss. Consequently, for high rates of real wage growth, the UVs will raise the hiring rates of the longterm unemployed without significantly reducing the retention rates of the currently employed workers.

\footnotetext{
${ }^{8}$ It depends on such factors as the relative magnitudes of skilled and unskilled employment, the wage differential between these two types of employment and the relative influence of job search on the probability of finding unskilled versus skilled jobs.

${ }^{9}$ It depends on such factors as the relative magnitudes of long-term and short-term unemployment, the responsiveness of the hiring probability to changes in job search and the responsiveness of the firing probability to changes in work effort.
} 


\section{UNEMPLOYMENT VOUCHERS VERSUS LOW-WAGE SUBSIDIES}

On the other hand, the greater an individual's real wage growth, the smaller is the influence of LWSs on an individual's incentive to seek and keep work. The high rates of wage growth provide the dominant incentives in these regards, making it more difficult for LWSs to play an employment-promoting role.

These considerations suggest that LWSs and UVs should not be seen as alternatives to one another, but might fruitfully be implemented together. The LWSs could help promote the employment of unskilled workers in dead-end jobs with flat intertemporal wage profiles, whereas the UVs could encourage employment at longer term, career jobs with the steeper profiles.

Finally, the paper will investigate the relative strengths and weakness of these two policies by addressing a simple question: For any given equity-efficiency objective (concerning living standards, unemployment, and wage disparities), what is the optimal dynamic structure of employment subsidies? Specifically, what is the optimal size distribution, duration, and targeting of employment subsidies?

Addressing this question turns out to be a straightforward and effective way of evaluating the relative appropriateness of the two approaches above. The low-wage subsidy approach is appropriate whenever the optimal employment subsidies (for a given equityefficiency objective) are (i) limitless over the duration of subsequent employment, (ii) constant in magnitude across unemployment and employment durations, and (iii) targeted at all workers receiving low wages. On the other hand, the employment voucher approach is appropriate whenever the optimal employment subsidies are (i) limited over the duration of subsequent employment, (ii) variable in magnitude across unemployment and employment durations (e.g. rising with the duration of unemployment and falling with the duration of subsequent employment), and (iii) targeted at the unemployed and particularly the long-term unemployed.

Not surprisingly, it turns out that the question above has no unconditional answer. The main contribution of the paper is to identify which economic circumstances favor which policy.

The question above tends to have been ignored in the analytical literature of labor market policies since the comparative analyses 
of these policies are generally undertaken in the context of static models ${ }^{10}$ or deterministic dynamic models. ${ }^{11}$

The static models, which are typically used in policy evaluations $^{12}$ are very problematic. These studies evaluate employment policies by assessing such statistics as how many people in the targeted group got jobs within a specified period of time (typically a quarter or a year), how many of these people would have gained employment without the policy within that period, how many incumbent employees (outside the target group) were displaced by the targeted workers within that period, and how many non-employed people outside the target group were left jobless within that period even though they would have found jobs in the absence of the policy. This framework inevitably focuses on short-run policy effects, largely ignoring the longer-run dynamic repercussions. Although the empirical evaluations do occasionally distinguish between short-run and long-run elasticities of labor demand, they generally do not examine the effects of the policy on the transition rates between employment and unemployment and between high-wage and low-wage jobs, and thus they are unable to evaluate the effects of the policy once the associated lagged adjustment processes have worked themselves out. ${ }^{13}$

On the other hand, the existing dynamic models of employment policies, such as those used in (Millard and Mortensen 1997) and (Hoon and Phelps 1997), have not been sufficiently detailed to permit the analysis of the critical issues identified above, namely, the optimal size distribution, duration, and targeting of the policies. It is these issues, we have argued that provide the acid test for judging the relative merits of unemployment vouchers and low-wage subsidies. In addition, these models have made some strategic simplifying assumptions (such as risk neutrality in (Millard and

\footnotetext{
${ }^{10}$ See, for example, ((Layard, Nickell, and Jackman 1991), pp. 490-2) and ((Snower 1994)).

${ }^{11}$ See, for example, (Millard and Mortensen 1997) using the matching model of (Mortensen and Pissarides 1994)) and ((Hoon and Phelps 1997) using the turnover training model in (Phelps 1994) (Hoon and Phelps 1992)).

${ }^{12}$ See, for example, ((NERA) 1997), ((NERA) 1995), (Martin Hanblin Research 1996), (Woodbury and Spiegelman 1987) and (Institute for Employment Studies 1994).

${ }^{13}$ The implicationsof this problem are examined in (Orszag and Snower 2000).
} 


\section{UNEMPLOYMENT VOUCHERS VERSUS LOW-WAGE SUBSIDIES}

Mortensen 1997) and workers being fully insured against job loss in (Hoon and Phelps 1997)) that are not only critical in evaluating the relative merits of unemployment vouchers and low-wage subsidies, but are not applicable in a world where workers face imperfect capital markets and where existing job security legislation and unemployment benefit system provide imperfect insurance.

To analyze policies that are meant to reduce unemployment and working poverty, it is necessary (at bare minimum) to use models that examine the effects of these policies on people's transitions between employment and unemployment and between high-wage and low-wage jobs. Much of the existing literature is based on models that focus on one or the other of these transitions but not both. ${ }^{14}$ This paper examines both transitions, as well as the interaction between them. ${ }^{15}$

Furthermore, it is important to keep in mind that unemployment and working poverty become especially severe social problems only when they are concentrated on a minority of people, trapped in these states for long durations. Thus policies addressing these problems must be analyzed through models that explicitly take account of how people's labor market behavior depends on their duration in various labor market states. While the existing policy literature largely ignores this important issue, this paper represents an attempt to take some salient duration influences into account.

\section{The Dynamic Structure of the Model}

There are many skill-types of worker in our model but workers enter the labor market with a given skill type so we focus our attention here on the decisions of a worker in a given skill group. Each worker of a given skill type in our model can pass through various labor market states, as illustrated in Figure (1). All workers die (leave the labor force permanently) with probability $d$ each period. A worker who has been unemployed for $j$ periods is hired with probability $h_{j}$; otherwise, the worker will either die or be unemployed for $j+1$ periods the next period. An employee who

\footnotetext{
${ }^{14}$ For instance, (Millard and Mortensen 1997) and (Hoon and Phelps 1997) consider the former, but not the latter, transitions.

${ }^{15}$ For example, high-wage jobs tend to be associated with larger retention rates than low-wage jobs.
} 


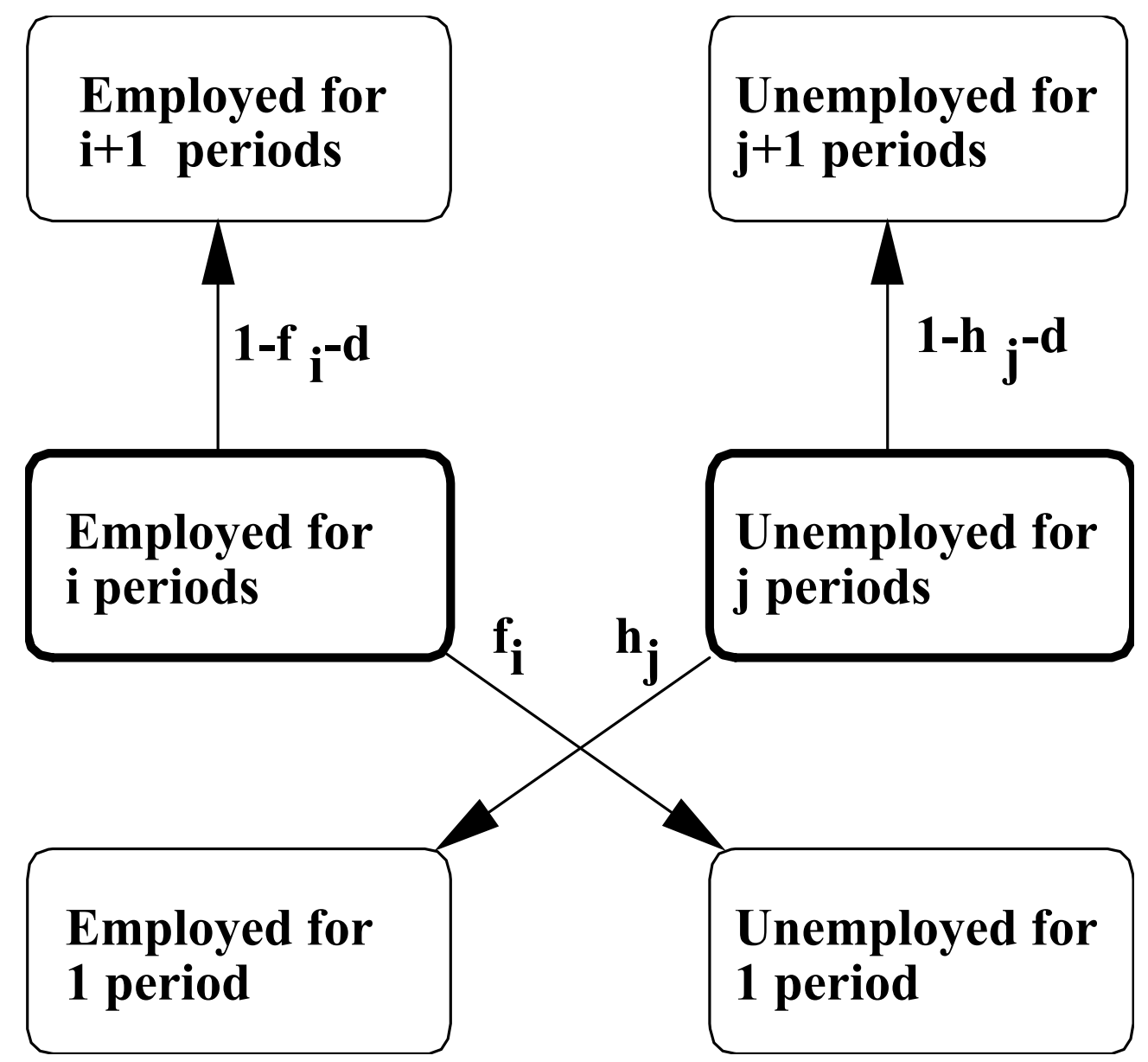

FiguRE 1. The structure of the model.

has been employed for $i$ periods faces a probability $f_{i}$ of becoming unemployed, a probability $d$ of dying and a probability $1-f_{i}-d$ of retaining a job and becoming employed for $i+1$ periods.

The resulting first-order condition is

$$
u_{l_{j u}}=-\beta h_{j}^{\prime}\left(l_{j u}\right)[V(1, e)-V(j+1, u)]
$$

In other words, the marginal utility of leisure must be set equal to the discounted marginal hiring propensity $\left(-\beta h_{j}^{\prime}\right)$ times the 


\section{UNEMPLOYMENT VOUCHERS VERSUS LOW-WAGE SUBSIDIES}

penalty for not finding a job $(V(j+1, u)-V(1, e))$. Since there is diminishing marginal utility of leisure, the optimal level of leisure depends inversely on the penalty for job loss.

The decision making problem of an employed worker may be expressed along analogous lines. Let $l_{i e}$ be the leisure of a worker who has been employed for $i<I$ periods and $f_{i}=f_{i}\left(l_{i e}\right)$ be that worker's separation rate. Let $w_{i}$ be the pre-tax wage and $w_{i}^{*}$ be the after-tax wage.

Then, since the worker makes decisions based on the after-tax wage $w_{i}^{*}$, his current utility is $u\left(w_{i}^{*}, l_{i e}\right), u_{12} \geq 0$. Moreover, let $V(i, e)$ be the present value associated with being employed for duration $i$, and $V(1, u)$ be the value of becoming unemployed. The worker's decision making problem is to solve

$$
\begin{aligned}
V(i, e) & =\max _{l_{i e}}\left[u\left(w_{i}^{*}, l_{i e}\right)\right. \\
& \left.+\beta\left(f_{i}\left(l_{i e}\right) V(1, u)+\left(1-f_{i}\left(l_{i e}\right)-d\right) V(i+1, e)\right)\right]
\end{aligned}
$$

The associated first-order condition is

$$
u_{l_{i e}}=\beta f_{i}^{\prime}\left(l_{i e}\right)[V(i+1, e)-V(1, u)] .
$$

Here, the marginal utility of leisure must be set equal to the discounted marginal firing propensity $\left(-\beta f_{i}^{\prime}\right)$ times the penalty for job loss $(V(i+1, e)-V(1, u))$. Once again, diminishing marginal utility of leisure implies that the optimal level of leisure depends inversely on the penalty for job loss.

For individuals employed for $I$ periods or unemployed for $J$ periods, the optimization problems and first order conditions are similar to the ones given above, with one exception. The exception concerns boundary conditions: unemployment spells of more than $J$ periods and employment spells of more than $I$ periods are treated together (e.g., $V(I+1, e)=V(I, e)$ and $V(J+1, u)=V(J, u))$.

According to Eq. (1) and Eq. (3), the primary inducement which leads workers to look for jobs and to work hard on the job is the difference between value of being employed and unemployed. Policies which increase this difference for both the employed and the unemployed will stimulate employment. 


\section{A Specific Analytical Example}

We now consider a specific example of the model above, with linear hire and separation rate funtions:

$$
\begin{gathered}
h_{j}\left(l_{j u}\right)=\theta_{j}\left(1-a l_{j u}\right) . \\
f_{i}\left(l_{i e}\right)=\phi_{i} l_{i e}
\end{gathered}
$$

(Microfoundations for these functions are provided in Appendix D.)

These functions are reduced forms and we focus here on on the worker's decisions, given the parameters of the hiring and firing functions that are under the firm's control. For these hiring and firing functions, let us derive the worker's leisure decision when unemployed $\left(l_{j u}\right)$ and employed $\left(l_{i e}\right)$. Suppose that the unemployed and employed workers have the same instantaneous utility function,

$$
u(c, l)=\frac{\left(c^{\alpha} l^{1-\alpha}\right)^{\gamma}}{\gamma} .
$$

where $c$ is the consumption and $l$ is the leisure of any worker. Since the worker is assumed to consume all his current income, $c=b$ for an unemployed worker (where $b$ is the unemployment benefit) and $c=w_{i}^{*}$ for an employed worker (where $w_{i}^{*}$ is the after-tax wage), and $b_{j}$ and $w_{i}^{*}$ are predetermined when the workers make their leisure decisions.

Substituting the derivatives of Eq. (6) and (4) into Eq. (1), we obtain the optimum interior choice of leisure when unemployed as: ${ }^{16}$

$$
l_{j u}=\left[\frac{\beta a \theta_{j}}{1-\alpha}(V(1, e)-V(j+1, u))\right]^{\frac{1}{(1-\alpha) \gamma-1}} b_{j}^{-\frac{\alpha \gamma}{(1-\alpha) \gamma-1}}
$$

for $1 \leq j<J$ and:

${ }^{16}$ The hire rate in Eq. (4) must lie between 0 and $1-d$. This implies that:

$$
\frac{1}{a}\left[1-\frac{1-d}{\theta_{j}}\right] \leq l_{j} \leq \frac{1}{a}
$$




$$
l_{J u}=\left[\frac{\beta a \theta_{j}}{1-\alpha}(V(1, e)-V(J, u))\right]^{\frac{1}{(1-\alpha) \gamma-1}} b_{J}^{-\frac{\alpha \gamma}{(1-\alpha) \gamma-1}}
$$

For those employed, the first order conditions Eq. (3) and our specific functional forms lead to a solution for leisure when employed of: ${ }^{17}$

$$
l_{i e}=\left[\frac{\beta \phi}{1-\alpha}(V(i+1, e)-V(1, u))\right]^{\frac{1}{(1-\alpha) \gamma-1}}\left[w_{i}^{*}\right]^{-\frac{\alpha \gamma}{(1-\alpha) \gamma-1}}
$$

for $1 \leq i<I$ and:

$$
l_{I e}=\left[\frac{\beta \phi}{1-\alpha}(V(I, e)-V(1, u))\right]^{\frac{1}{(1-\alpha) \gamma-1}}\left[w_{I}^{*}\right]^{-\frac{\alpha \gamma}{(1-\alpha) \gamma-1}} .
$$

These first order conditions are then substituted back into the optimal value equations and a solution for the value function is then derived. From the value function solution, hire and fire rates are determined using Eqs. (4) and (5). In Appendix A, we solve this model in closed-form (albeit with some strong parameter restrictions, but for arbitrary $I$ and $J$ ) and we show that the solution when the parameters of the model are duration-independent is:

$$
\begin{aligned}
& V(i, e)=\bar{V}(e)=\left[\frac{\left(1+\frac{F_{2}}{1-F_{1}}\right)}{\left[\frac{G_{0}}{1-G_{1}}-\frac{F_{0}}{1-F_{1}}\right]}\right]^{\frac{z}{z-1}} \frac{G_{0}}{1-G_{1}} \\
& V(j, u)=\bar{V}(u)=\bar{V}(e)-\left[\frac{\left(1+\frac{F_{2}}{1-F_{1}}\right)}{\left[\frac{G_{0}}{1-G_{1}}-\frac{F_{0}}{1-F_{1}}\right]}\right]^{\frac{1}{z-1}}
\end{aligned}
$$

where $z-1=\frac{1}{(1-\alpha) \gamma-1}<0$,

$$
\begin{aligned}
& F_{0}=b^{\frac{-\alpha \gamma}{(1-\alpha) \gamma-1}}(\beta a \theta)^{\frac{(1-\alpha) \gamma}{(1-\alpha) \gamma-1}}\left[\frac{1}{1-\alpha}\right]^{\frac{1}{(1-\alpha) \gamma-1}}\left(\frac{1}{\gamma}\left[\frac{1}{1-\alpha}\right]-1\right) \\
& F_{1}=\beta(1-d), F_{2}=\beta \theta, \\
& G_{0}=\left(w^{*}\right)^{\frac{-\alpha \gamma}{(1-\alpha) \gamma-1}}(\phi \beta)^{\frac{(1-\alpha) \gamma}{(1-\alpha) \gamma-1}}\left[\frac{1}{1-\alpha}\right]^{\frac{1}{(1-\alpha) \gamma-1}}\left(\frac{1}{\gamma}\left[\frac{1}{1-\alpha}\right]-1\right), \text { and } \\
& G_{1}=\beta(1-d) .
\end{aligned}
$$

\footnotetext{
${ }^{17}$ The hire rate in Eq. (9) must lie between 0 and $1-d$ so that $0 \leq l_{i e} \leq \frac{1-d}{\phi_{i}}$.
} 


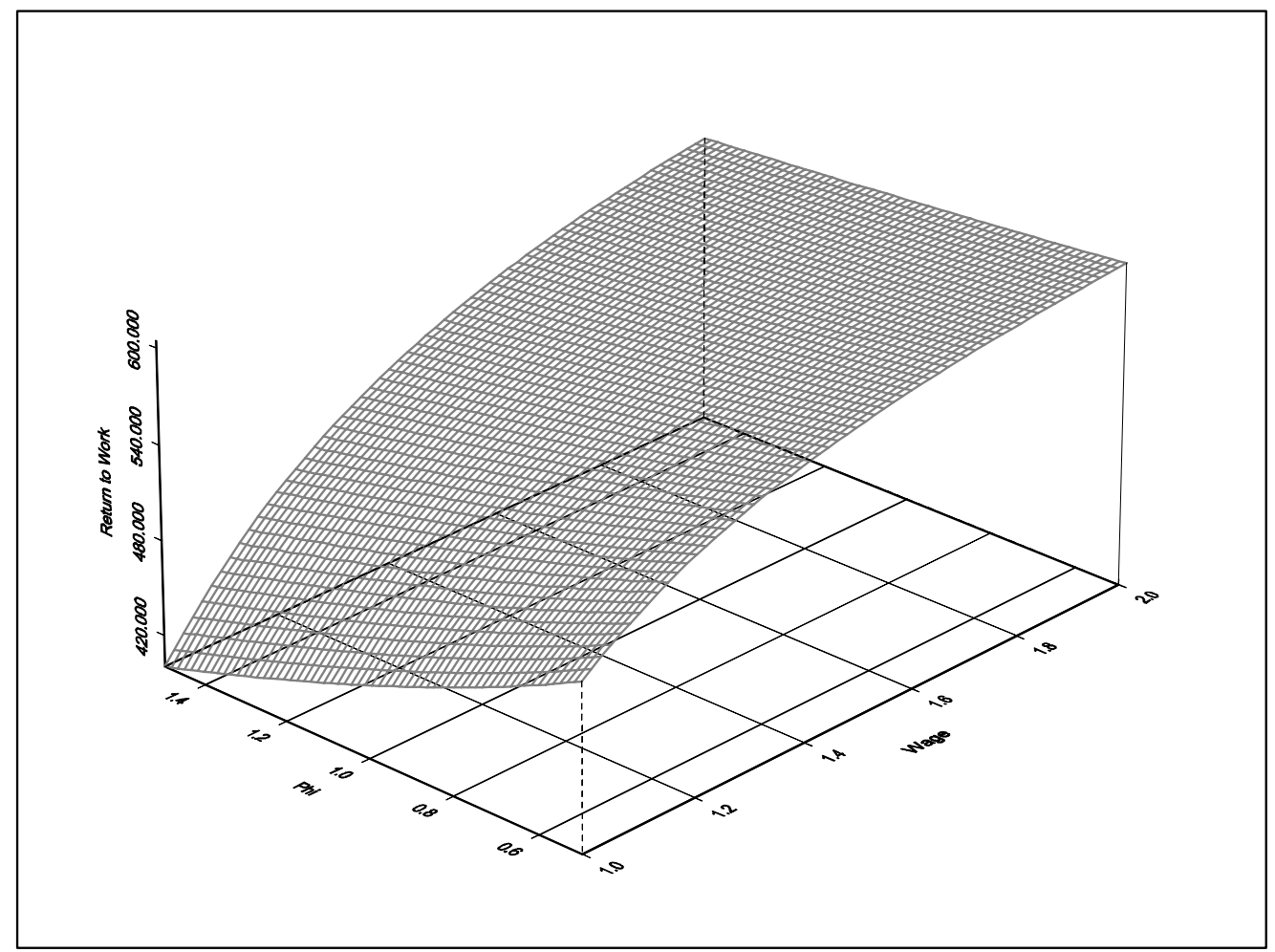

FiguRE 2. The effect of changes in wages and $\phi$ on the reward to work.

While this is a closed-form solution, its structure is rather complex and it is useful to consider the properties of the model with respect to variations in parameters, before proceeding to consider optimal duration-dependent policy. To determine such baseline parameters, we let the period of analysis be one quarter and select a coefficient of relative risk aversion of $10, \alpha=0.8, \beta=0.98$, $\phi=0.7, a=1.0, \theta=0.75, b=0.4, w^{*}=1.5, d=0.005$. In this case, the baseline unemployment rate is $8.4 \%$ with a fire rate of $1.6 \%$ and a hire rate of $23.5 \%$.

To evaluate the reasonableness of these parameters, we define the long term unemployed to be those unemployed for at least a year (4 periods). As shown in Appendix B, if the transition rate 


\section{UNEMPLOYMENT VOUCHERS VERSUS LOW-WAGE SUBSIDIES}

out of unemployment is a constant $h$, then the steady state proportion of people who are unemployed for more than $x$ periods is $(1-h)^{x}$. Thus, the fraction of the unemployed who are long-term unemployed is $(1-h)^{4}$. In Britain, roughly $36 \%$ of the unemployed have been jobless for over a year: $(1-h)^{4}=0.36$, where $h$ is deadweight (the hire rate in the absence of vouchers). This suggests that, under our Markov assumptions, the deadweight parameter is 0.2254 which is very close to our hire rate of $23.5 \%$.

Furthermore, it can be shown ${ }^{18}$ that if the rate of outflow from unemployment is $h$, then the mean duration of an unemployment spell is $\frac{1}{h}$. Our separation rate is 0.016 thus corresponds to an average job tenure of roughly ten years (this is well below the average tenure of 15 years reported for UK men by (Burgess and Rees December 1994)).

The effects of important parameter variations are shown in Figs. (2) - (5). Fig. (2) shows the effects of simultaneous changes of wages and $\phi$. A higher wage clearly raises the reward to work whereas a higher employer firing propensity (higher $\phi$ ) lowers the reward to work; there is also some complementarity between higher wages and less monitoring as workers are willing to trade off lower wages for less strenuous working conditions. Fig. (??) depicts the corresponding effects of changes in $\phi$ and wages on aggregate unemployment. A rise in wages increases the reward to work and lowers unemployment whereas the opposite is true for an increase in $\phi$.

Two of the most important factors in determining the reward to work are the discount factor and risk aversion. Fig. (4) shows that a higher discount factor raises the reward to work. This is because, given a profile of wages and benefits, workers who have less timepreference, see greater gains from working. Fig. (5) shows that higher relative risk aversion increases the reward to work. Risk averse workers attach a higher utility penalty for losing their jobs

\footnotetext{
${ }^{18}$ To see this, observe that $(1-f)^{x} v_{0}^{s}$ is the number of people who have been employed for $x$ periods, where $v_{0}^{s}$ is the steady state number of entrants to employment. The probability of being fired after $x$ periods is therefore $f(1-$ $f)^{x-1}$. Thus, the mean duration of unemployment is: $\sum_{x=1}^{\infty} x f(1-f)^{x-1}$. Noting that the mean duration of employment is $f$ times $\sum_{x=1}^{\infty}(1-f)^{x}=\frac{1}{f}-1$, we arrive at the result by differentiation.
} 


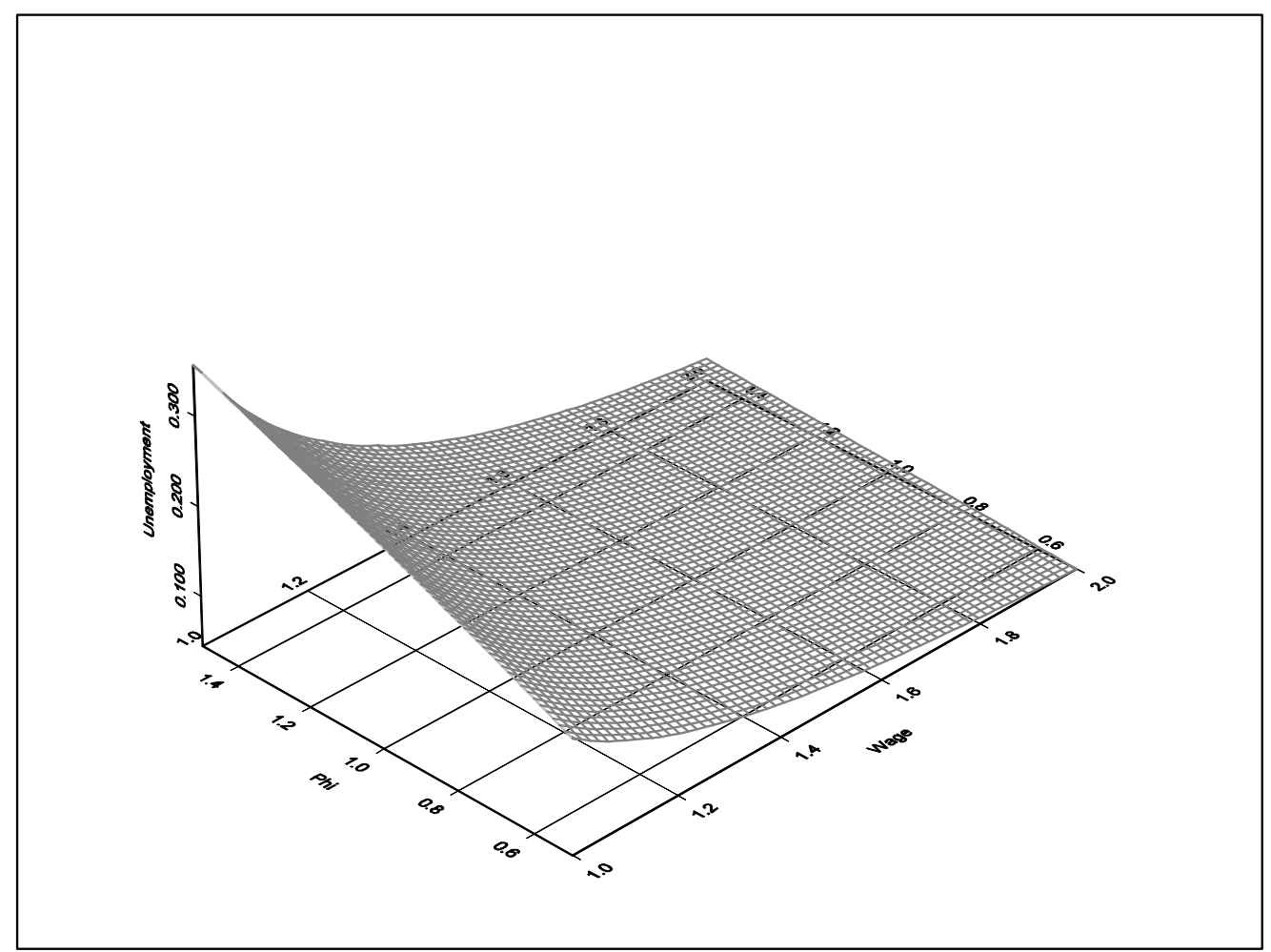

Figure 3. The effect of changes in wages and $\$ \backslash$ protect $\backslash$ phi $\$$ on unemployment.

and hence the reward to work is higher in utility terms for risk averse workers.

\section{The Effects of Unemployment Vouchers and Low-Wage Subsidies}

The analytical solution from the previous section only holds under the restrictive condition of duration-independent parameters and hence does not enable the practical analysis of durationdependent employment policy. We therefore solve our model numerically, taking into account the constraints that hire and fire rates must be between 0 and $1-d$. Details of the numerical procedures are in Appendix C. 


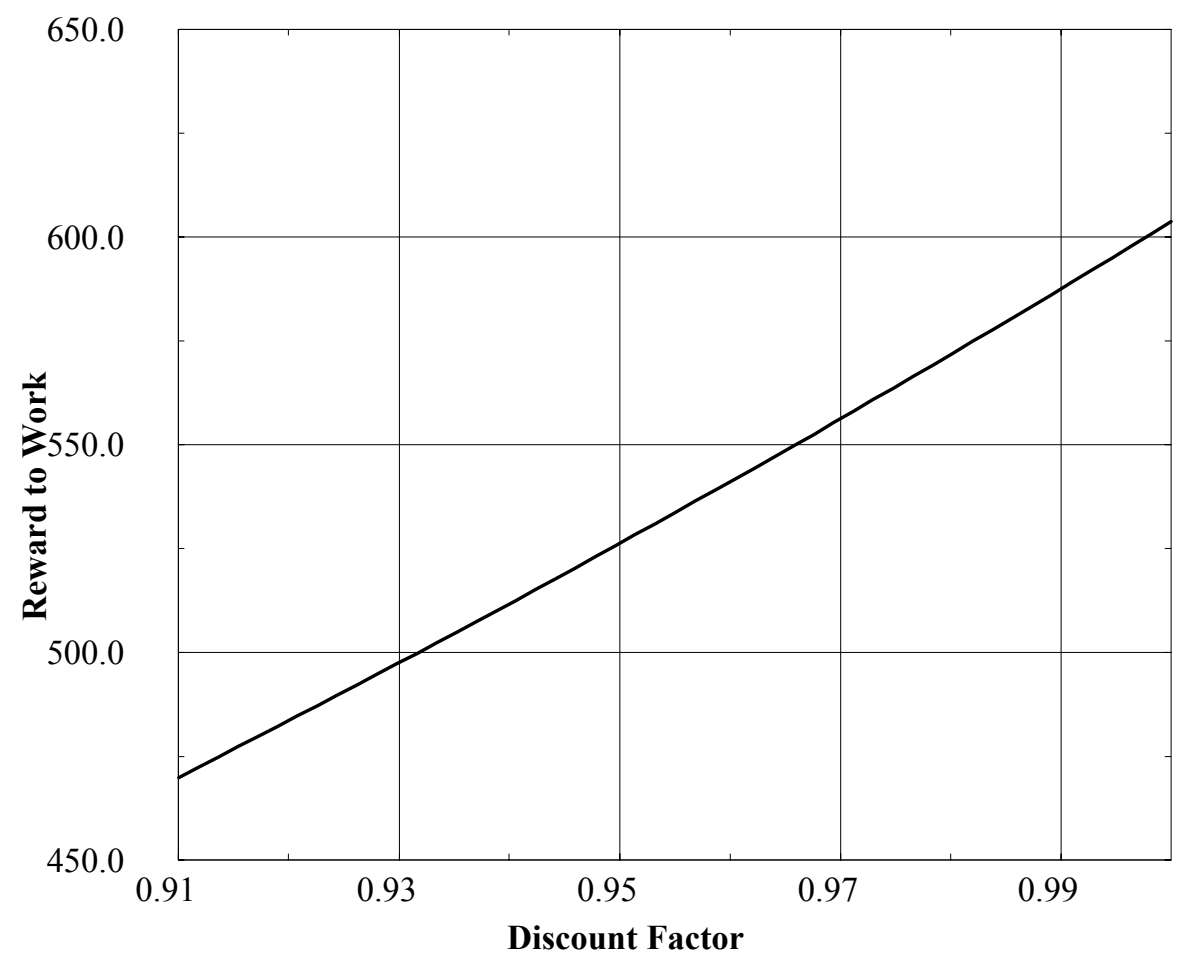

Figure 4. The effect of changes in the discount factor on the reward to work.

We compare the economic implications of the following two policies:

- Unemployment Vouchers: Unemployed workers, upon receiving a job, receive a two-year voucher.

- Low-wage Subsidies: Low-skill (low-wage) workers receive a subsidy of unlimited duration.

We examine the influence of these two policies on two types of workers:

- "Dead-end workers:" These workers are trapped indefinitely in low-wage (low-productivity) jobs, on account of their irremedially low skills. 


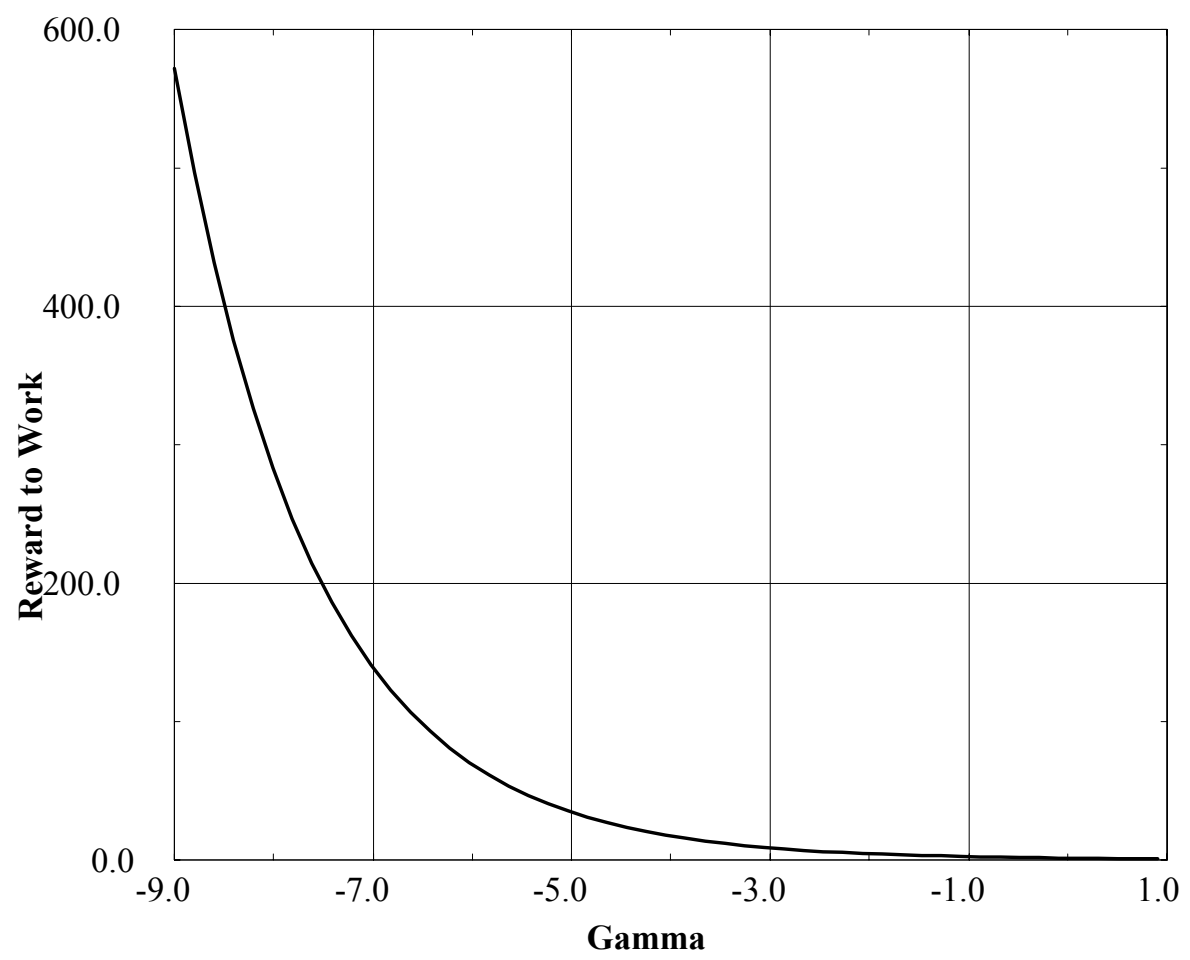

FiguRE 5. Effect of changes of $\gamma$ on the reward to work.

- "Upwardly mobile workers": These workers experience are rise in their wages after a period of on-the-job experience, on account of either on-the-job training or market power acquired within the firm.

As we shall see, the two policies have radically different effects on these two groups.

5.1. Dead-End Workers. We compare a two-year voucher of $50 \%$ of the initial wage and a wage subsidy of $7.2 \%$. Both have equivalent effects on the government budget.

Fig. (6) shows the effect of the voucher on the value of employment whereas Fig. (7) shows the corresponding effects with a 


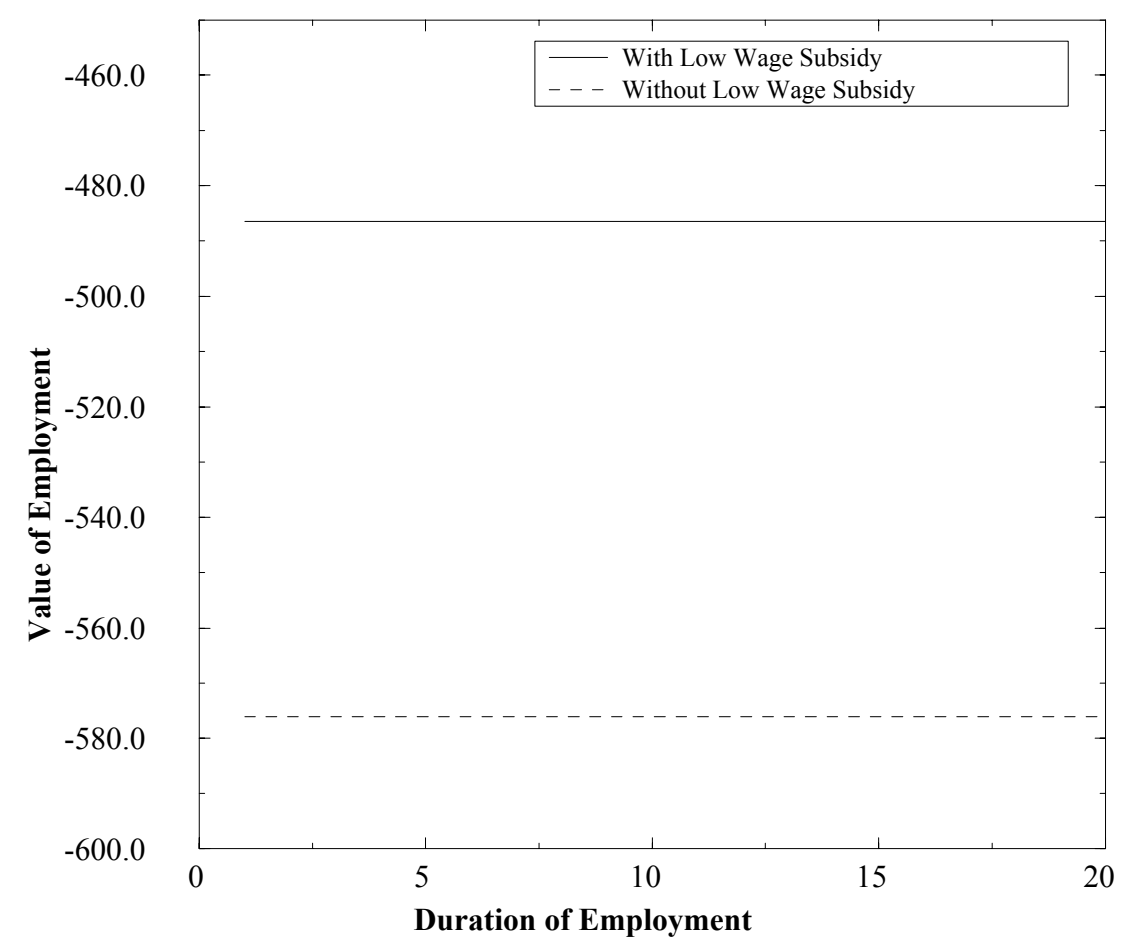

Figure 6. Value of being employed with and without an unemployment voucher.

low-wage subsidy. Figs. (8) and Fig. (9) show the corresponding effects on the value of unemployment.

The direct effect of the voucher is to raise the value of employment for workers and encourage workers to find jobs. However, it does so more at short durations than at long durations. At long employment durations, the value of employment still rises because workers who are long-term employed and become unemployed will have access to a voucher. On the other hand, the low-wage subsidy has the same effect on the value of employment at all durations. Both the unemployment voucher and the lowwage subsidy increase the value of unemployment but the voucher does so more because the voucher payments are front-loaded. The 


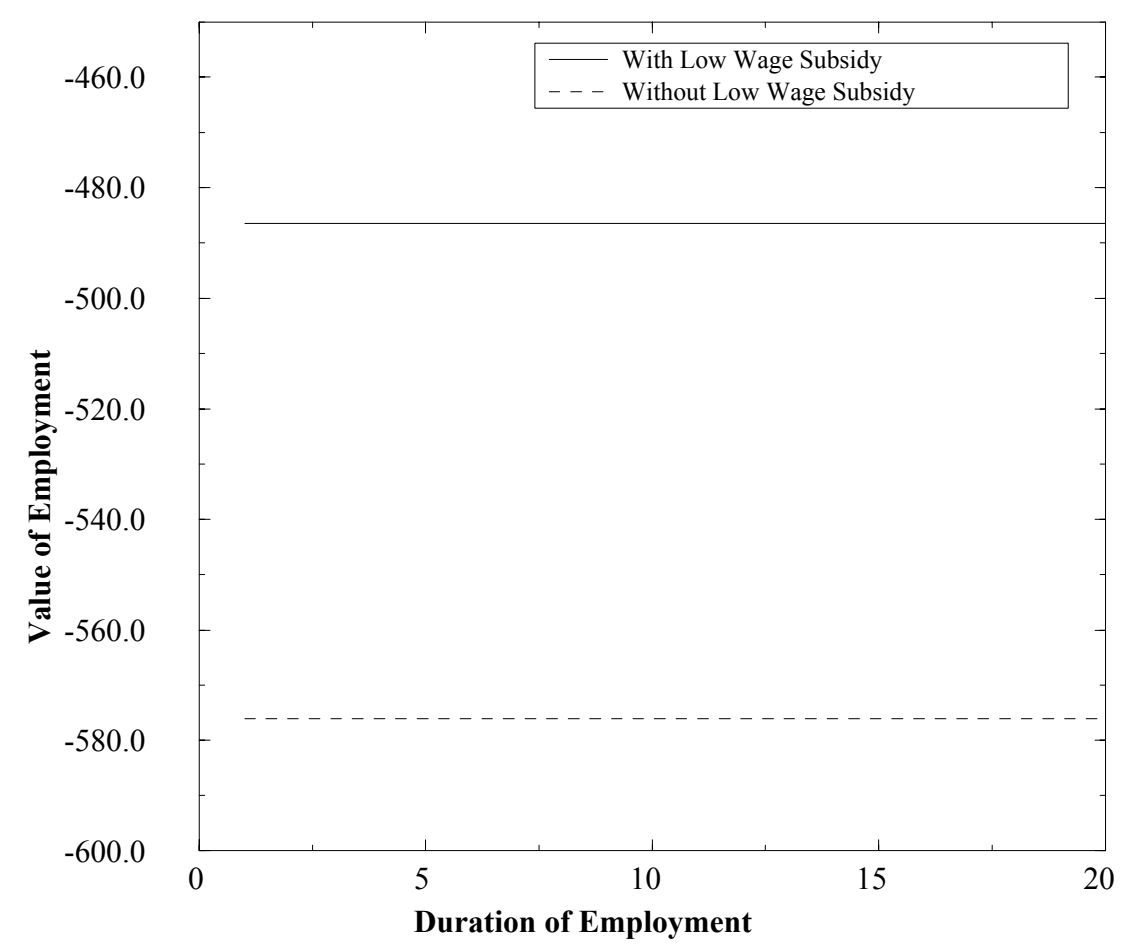

FIGURE 7. Value of being employed with and without an unemployment voucher.

increase in the value of unemployment is an indirect effect which reduces the incentives for workers to stay in their current jobs which works against the direct effects of unemployment vouchers and wage subsidies in reducing unemployment.

The unemployment voucher and the low-wage subsidy have differential effects on the duration distribution of employment and unemployment. The unemployment voucher reduces the number of long-term unemployed whereas the low-wage subsidy has a bigger effect on encouraging long-term employment. In Fig. (11) and (11), we plot the effects of the unemployment voucher on the ratio of employment after the policy to employment before the policy. Fig. (12) and Fig. (13) are the corresponding plots for 


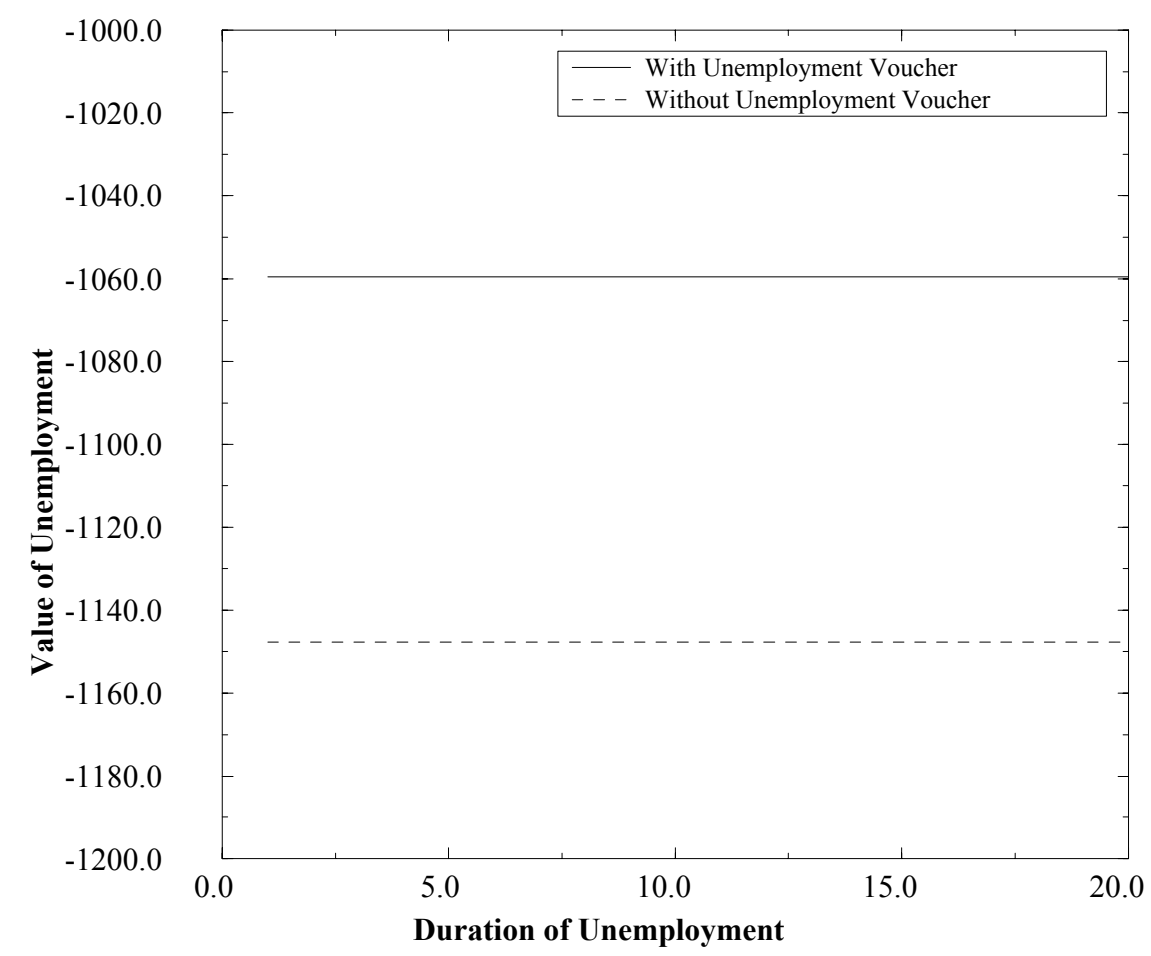

Figure 8. Value of being unemployed with and without an unemployment voucher.

the low-wage subsidy. The unemployment voucher results in unemployment of $7.8 \%$ compared with a decrease in unemployment from the baseline of $8.4 \%$. However the low-wage subsidy is more effective, reducing the unemployment rate to $7.3 \%$.

The reason for this difference is straightforward. As the figures above show, the low-wage subsidies imply that the discounted value of remaining employed remains constant as the duration of employment increases. By contrast, the unemployment vouchers imply that this discounted value falls as duration increases over the first two years of employment. The lesser unemployment influence of the unemployment vouchers thus arises because workers 


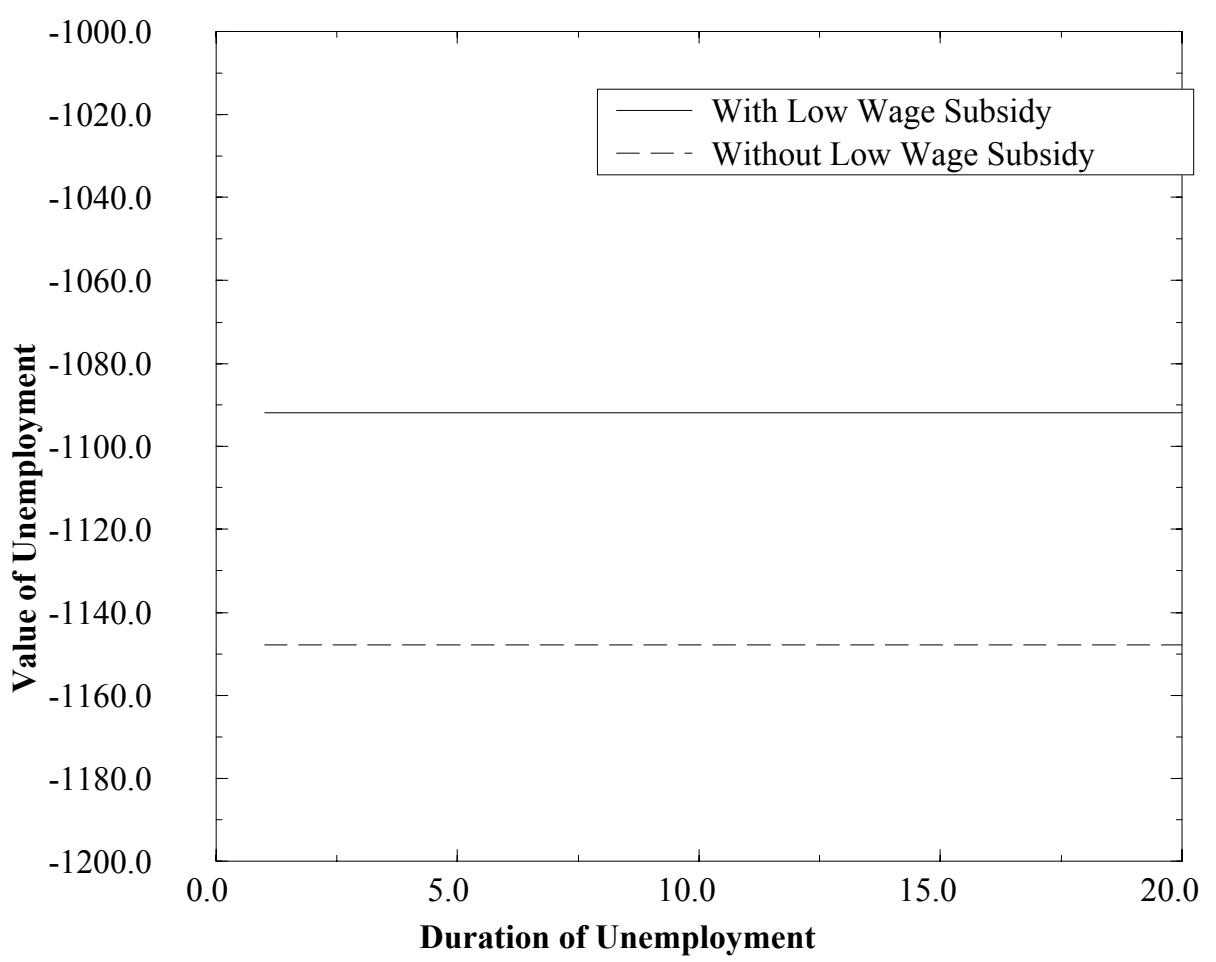

FiguRE 9. Value of unemployment at different durations with a low wage subsidy.

perceive lower values to remaining in work and therefore their separation rates rise with their duration of employment.

5.2. Upwardly Mobile Workers. The relative effectiveness of the two policies is quite different when workers are upwardly mobile. These workers, as noted, receive a significant reward to experience some time after entering their jobs. For instance, the longterm unemployed often experience a jump in earnings after they demonstrate their ability to work. Under these circumstances, the above disadvantage of the unemployment voucher policy is small, for the wage increase discourages workers from quitting their jobs in their first two years of employment. 


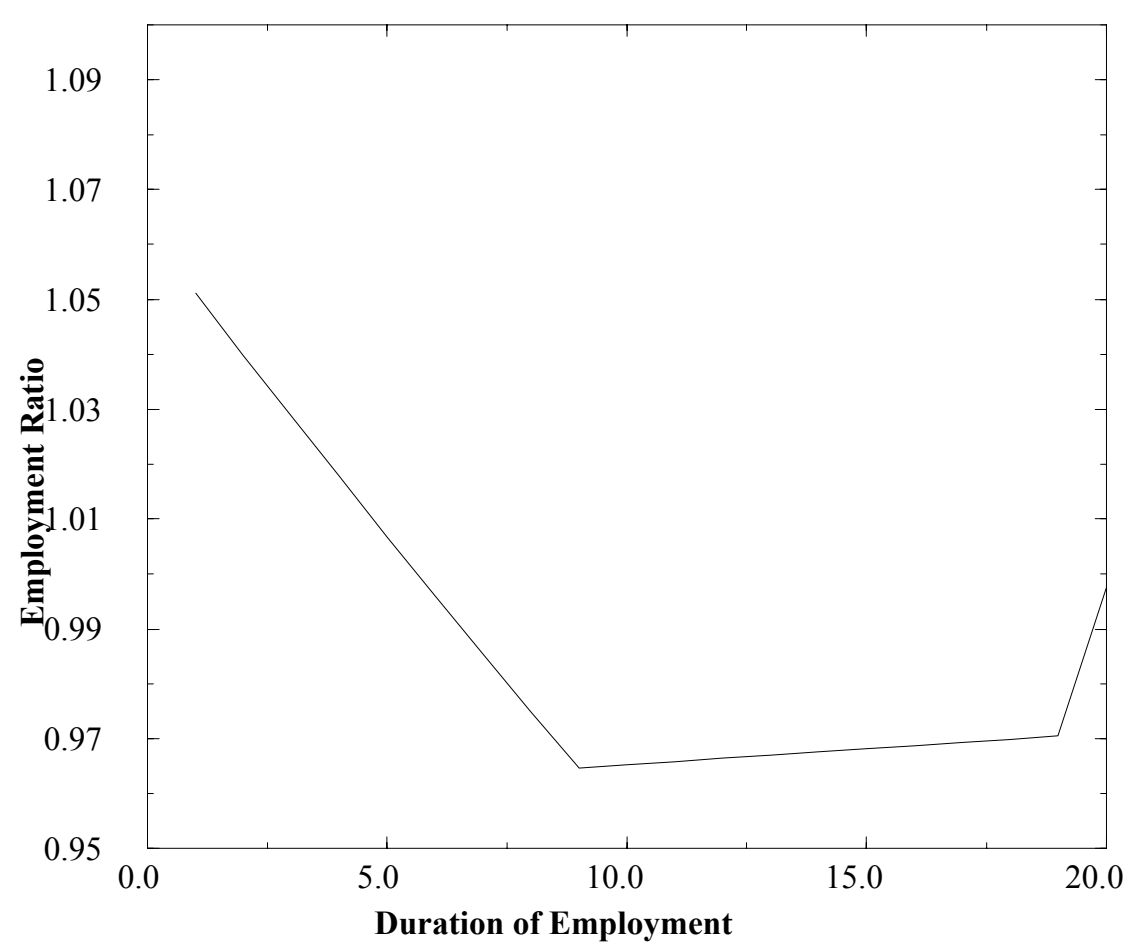

Figure 10. Change in employment at different durations with an unemployment voucher.

To model this effect in a simple way, we assume that an unemployed person receives a wage of 1.0 for the first two years after gaining employment, and then experiences a wage increase to 1.50. We consider an unemployment voucher of 0.50 and a low-wage subsidy of 0.077 , which have similar budgetary impacts.

Fig. (14) shows the effect of the unemployment voucher on the value of employment whereas Fig. (15) shows the corresponding effects with a low-wage subsidy. Figs. (16) and Fig. (17) likewise show the effects on the value of unemployment.

The direct effect of the voucher again is to raise the value of employment for workers and encourage workers to find jobs. However, it does so more at short durations than at long durations. 


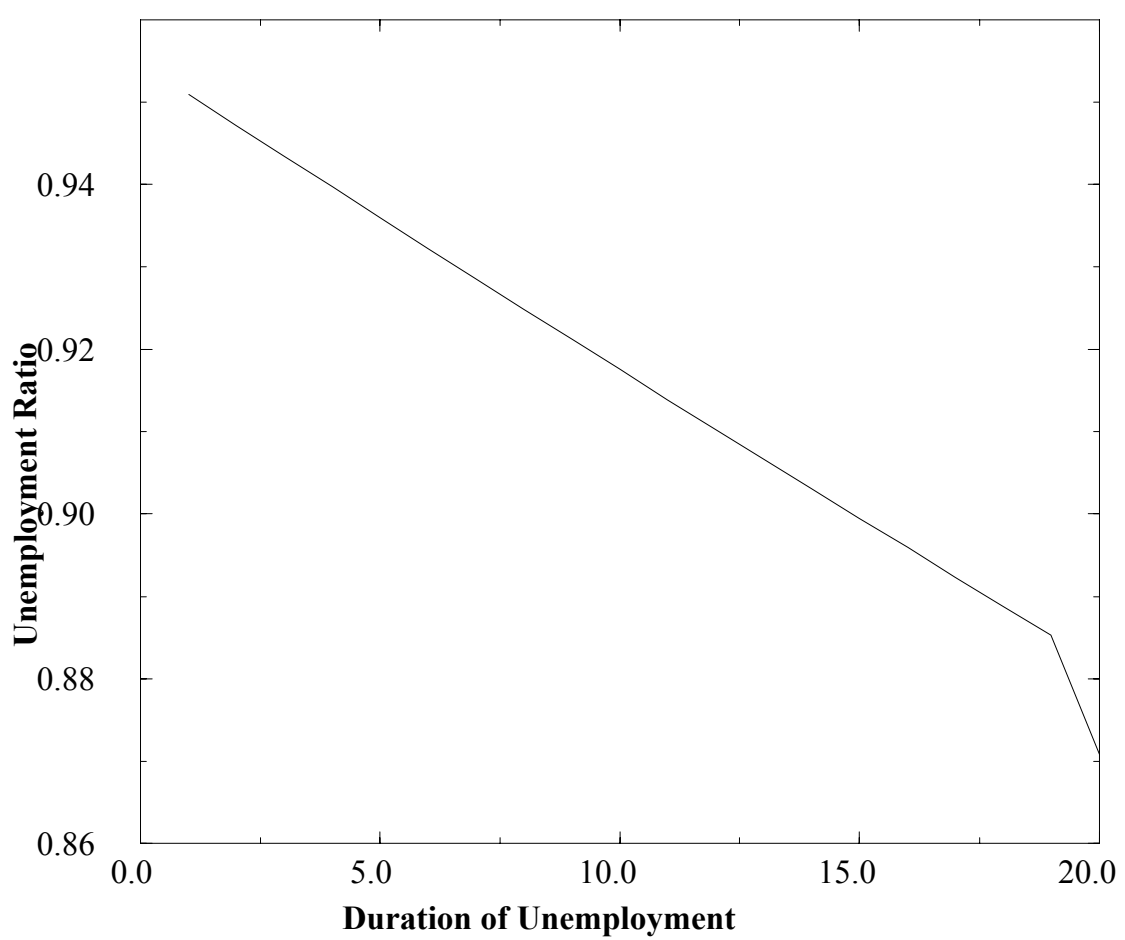

FiguRE 11. Change in unemployment at different durations with an unemployment voucher.

Consequently, in contrast to the dead-end worker case, the discounted value of employment does not fall in the initial two years, so that workers are encouraged to stay in work. Both the unemployment voucher and the low-wage subsidy increase the value of unemployment but the voucher does so more because the voucher payments are front-loaded. ${ }^{19}$ As the baseline unemployment rate is $10.0 \%$, the unemployment voucher reduces unemployment to $8.4 \%$, whereas with the low-wage subsidy reduces it to $8.7 \%$. The

\footnotetext{
${ }^{19}$ The increase in the value of unemployment is an indirect effect which reduces the incentives for workers to stay in their current jobs which works against the direct effects of unemployment vouchers and wage subsidies in reducing unemployment.
} 


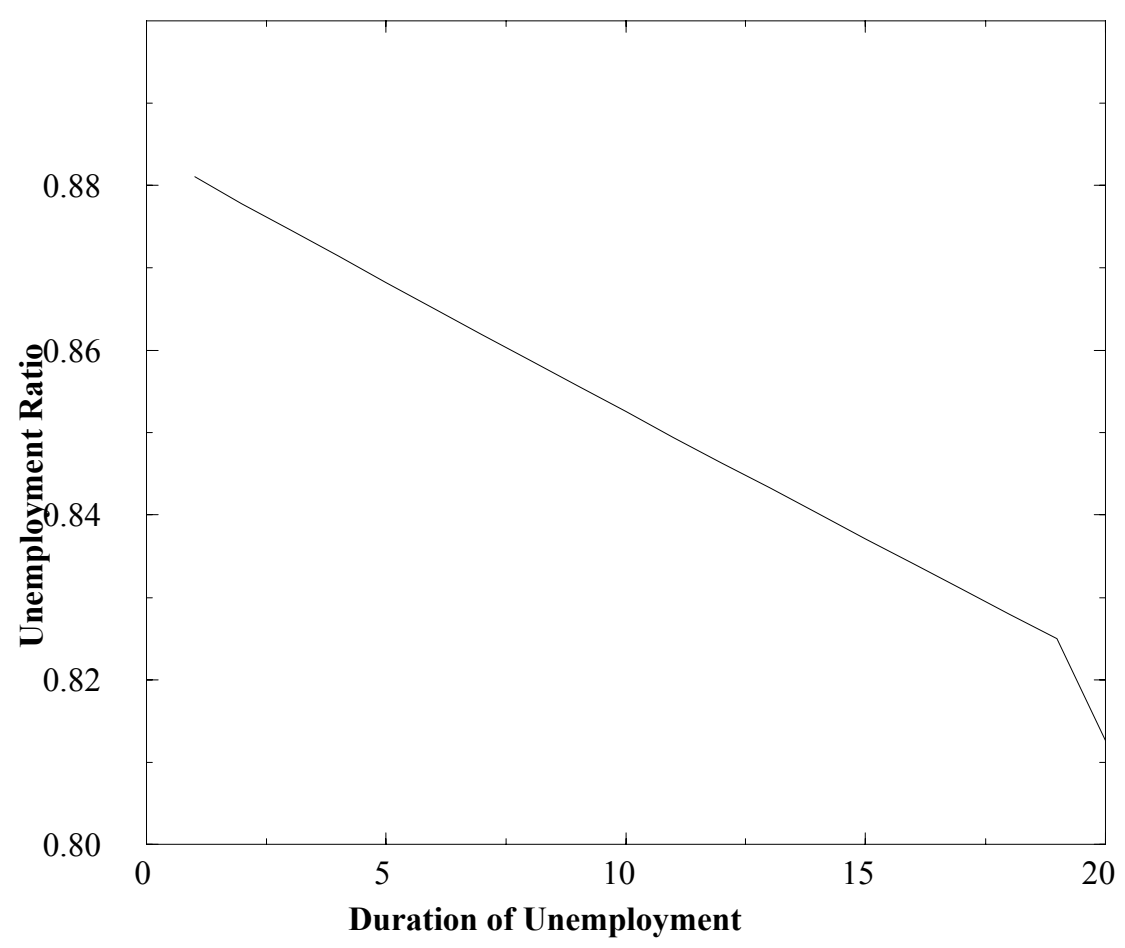

FIGURE 12. Ratio of unemployment with/without low wage subsidy policy at different durations.

unemployment voucher and the low-wage subsidy again have differential effects on the duration distribution of employment and unemployment. The unemployment voucher reduces the number of long-term unemployed, whereas the low-wage subsidy has a bigger effect on encouraging long-term employment. In Fig. (18) and (??), we plot the effects on the number employed and unemployed of a voucher. Fig. (20) and Fig. (21) are the corresponding plots for the low-wage subsidy.

The increase in the value of unemployment is an indirect effect which reduces the incentives for workers to stay in their current jobs which works against the direct effects of unemployment vouchers and wage subsidies in reducing unemployment. The voucher 


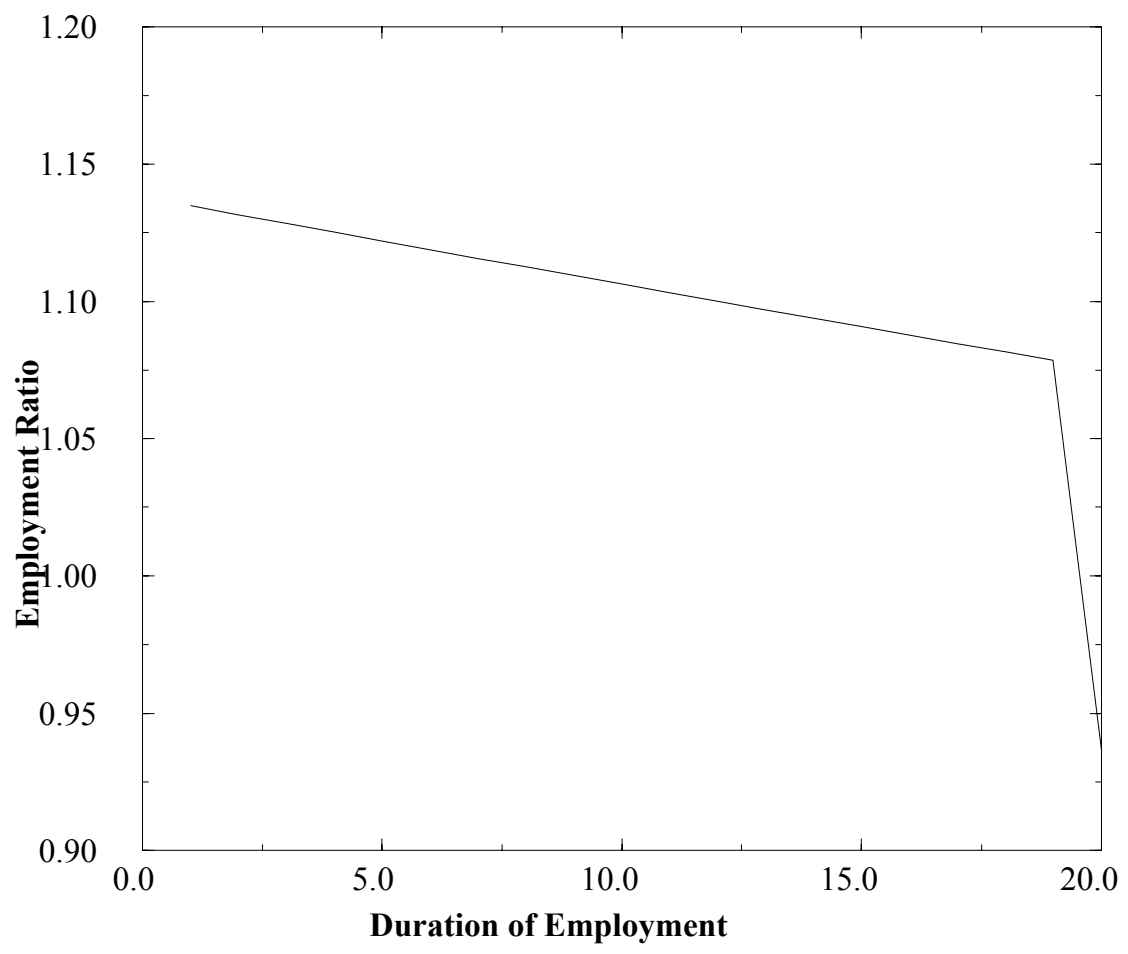

Figure 13. Change in employment at different durations with a low wage subsidy.

is more likely to be more effective the more upwardly mobile a worker expects to be (i.e. the more the worker expects his wage to increase in the future).

\section{Optimal Subsidy Policy}

It remains to examine optimal subsidies. We focus on two optimization criteria:

- Minimization of the number of long-term unemployed (those unemployed for more than 2 years).

- Maximization of aggregate welfare of low skill, low-wage groups (Benthamite). 
UNEMPLOYMENT VOUCHERS VERSUS LOW-WAGE SUBSIDIES

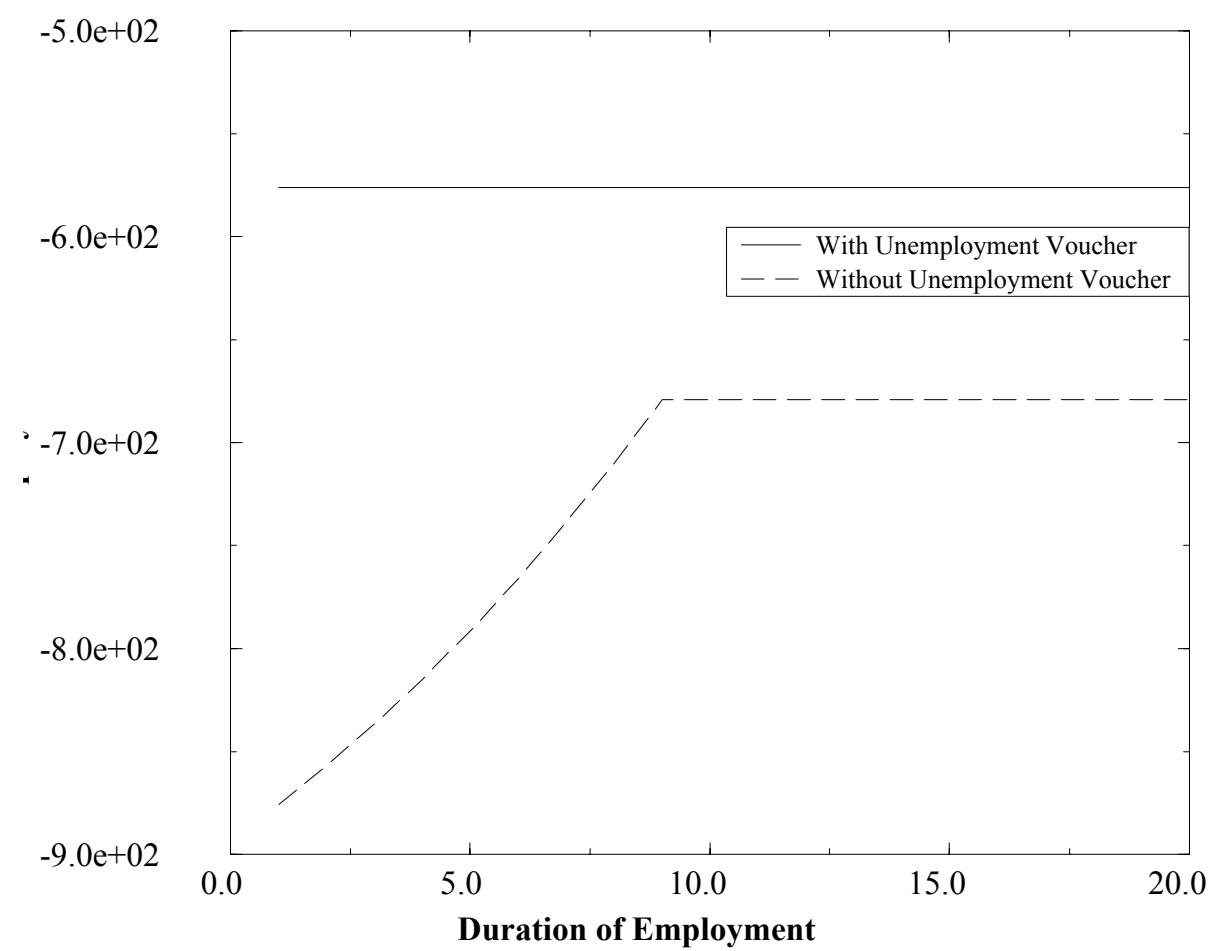

Figure 14. Value of being employed with and without an unemployment voucher.

The first criterion will more likely tend to lead to policies which stimulate most the welfare of the unemployed or short-term employed by providing them with incentives to find jobs whereas the second criteria seems to lead more naturally to policies which affect all workers. (We also have considered other criteria such as, for example, maximization of the welfare of the short-term employed (Rawlsian) or minimization of aggregate unemployment, but the results do not differ significantly from the two criteria above.)

For our optimization exercise, the government budget constraint is that the total expenditure on employment subsidies to the target 


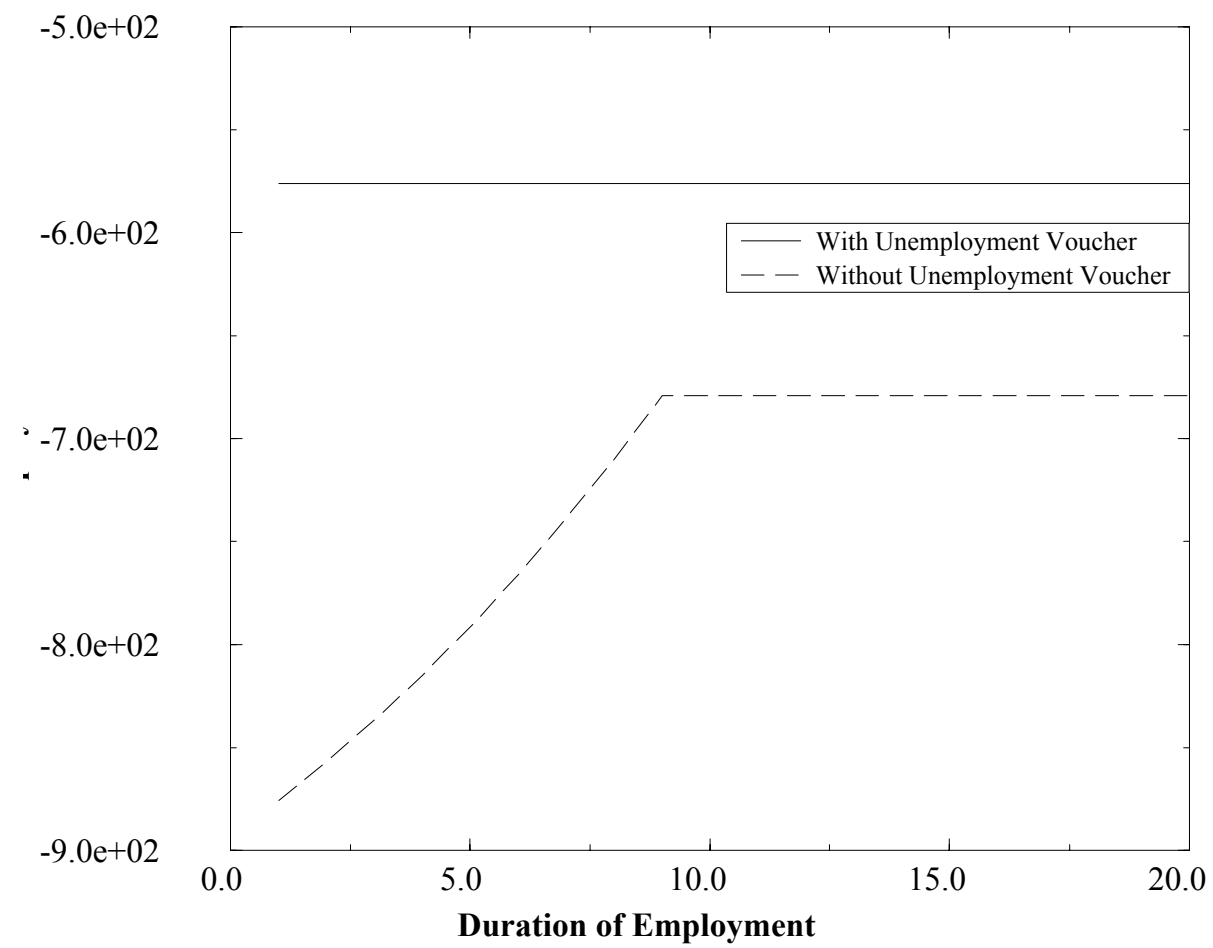

Figure 15. Value of employment at different durations with a low wage subsidy.

skill group is less than or equal to its total savings on unemployment benefits plus the amount the government receives in payroll taxes from other groups of workers and other budgetary sources:

$$
\sum_{i=1}^{n_{i}} \tilde{n}_{e}(i) v(i) \leq \sum_{j=1}^{n_{j}}\left(b(j) \tilde{n}_{u}(j)-b^{o}(j) \tilde{n}_{u}^{o}(j)\right)+g
$$

where $\tilde{n}_{e}(i)$ are the number of eligible workers employed for $i$ periods, $v(i)$ is the subsidy paid to them, $\tilde{n}_{u}(j)$ are the number of unemployed workers of duration $j$ eligible for benefits, $b(j)$ are the unemployed benefits paid, $\tilde{n}_{u}^{o}(j)$ are the number of duration $j$ originally eligible for benefits, $b^{\circ}(j)$ are the original level of benefits paid, and $g$ is the level of government spending. 
UNEMPLOYMENT VOUCHERS VERSUS LOW-WAGE SUBSIDIES

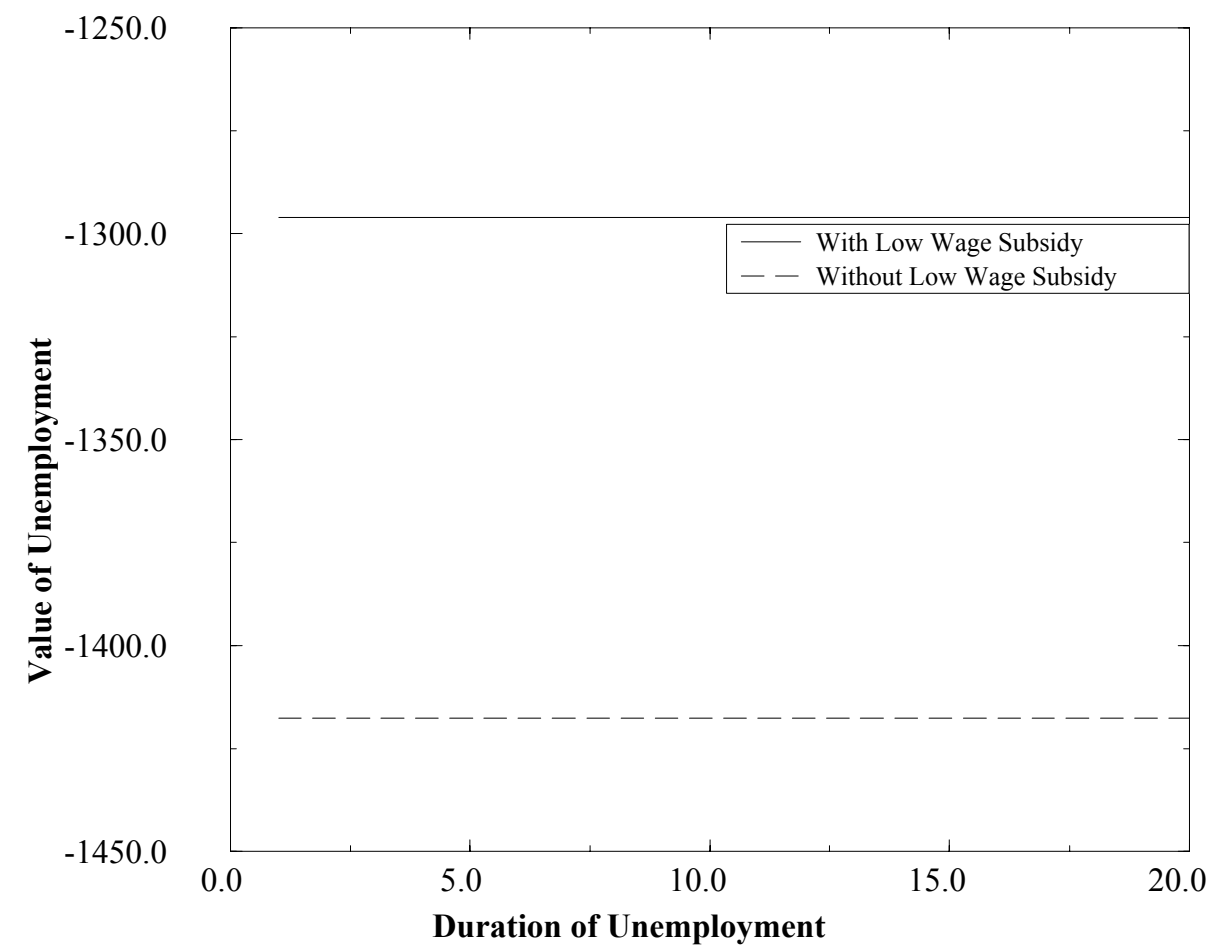

FiguRE 16. Value of being unemployed with and without an unemployment voucher.

For the dead-end worker case, the optimal subsidy is shown in Fig. (??). For the upwardly-mobile worker case, the corresponding optimal subsidy is shown in Fig. (??). Note that the optimal subsidy for the upwardly-mobile worker is very close to an unemployment voucher, whereas the optimal subsidy for the dead-end worker case is closer to a low-wage subsidy. ${ }^{20}$ Our results therefore suggest that the optimal policy depends tightly on the wage prospects of the newly employed.

\footnotetext{
${ }^{20}$ The optimal subsidy curve is actually upward sloping to incentivize workers to stay in their jobs.
} 


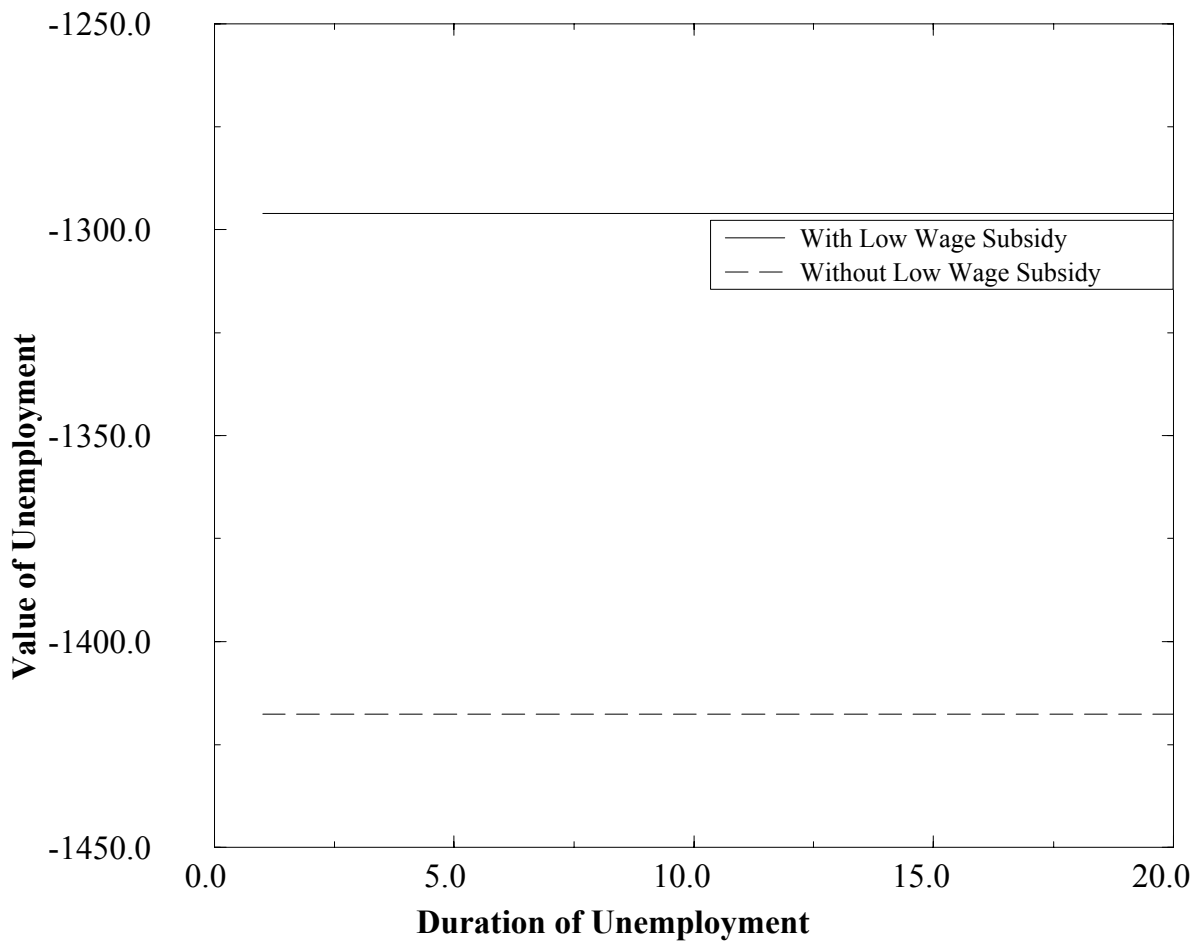

FiguRE 17. Value of unemployment at different durations with a low wage subsidy.

\section{Conclusion}

This paper has examined the effectiveness of unemployment vouchers and low-wage subsidies. Our analysis indicates that, if workers are upwardly mobile (i.e. they experience wages which will increase after a period of employment), unemployment vouchers are likely to be more effective than a low-wage subsidies both in terms of maximizing welfare of the low-skill workers and also in terms of minimizing unemployment. On the other hand, if workers are trapped indefinitedly in dead-end jobs with flat wage profiles, a low-wage subsidies perform better. 
UNEMPLOYMENT VOUCHERS VERSUS LOW-WAGE SUBSIDIES

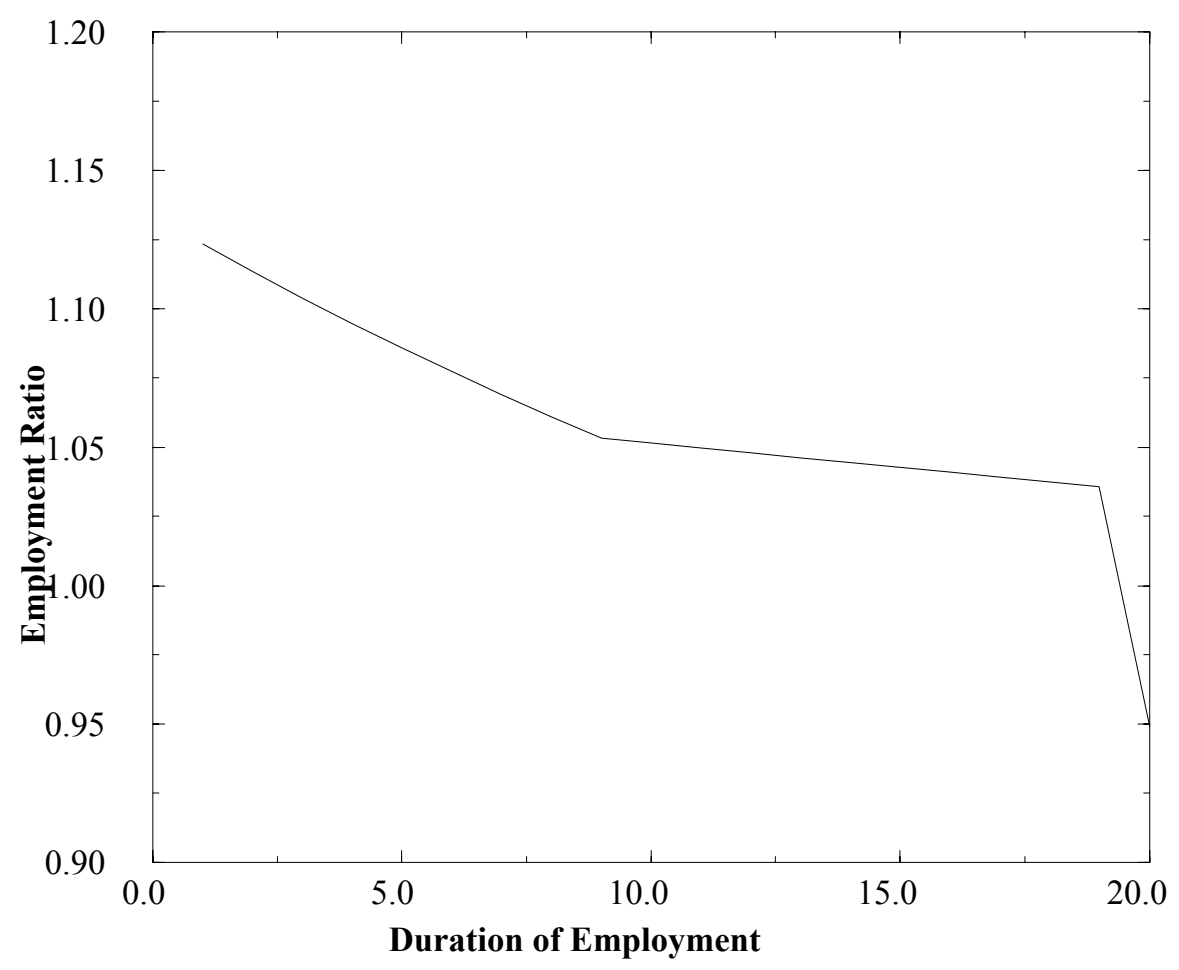

Figure 18. Change in employment at different durations with an unemployment voucher.

Appendix: A Closed Form Analysis of the Basic Consumer Model

Substituting Eqs. (7) - (10) into the value function equations (??) and (2), we obtain 


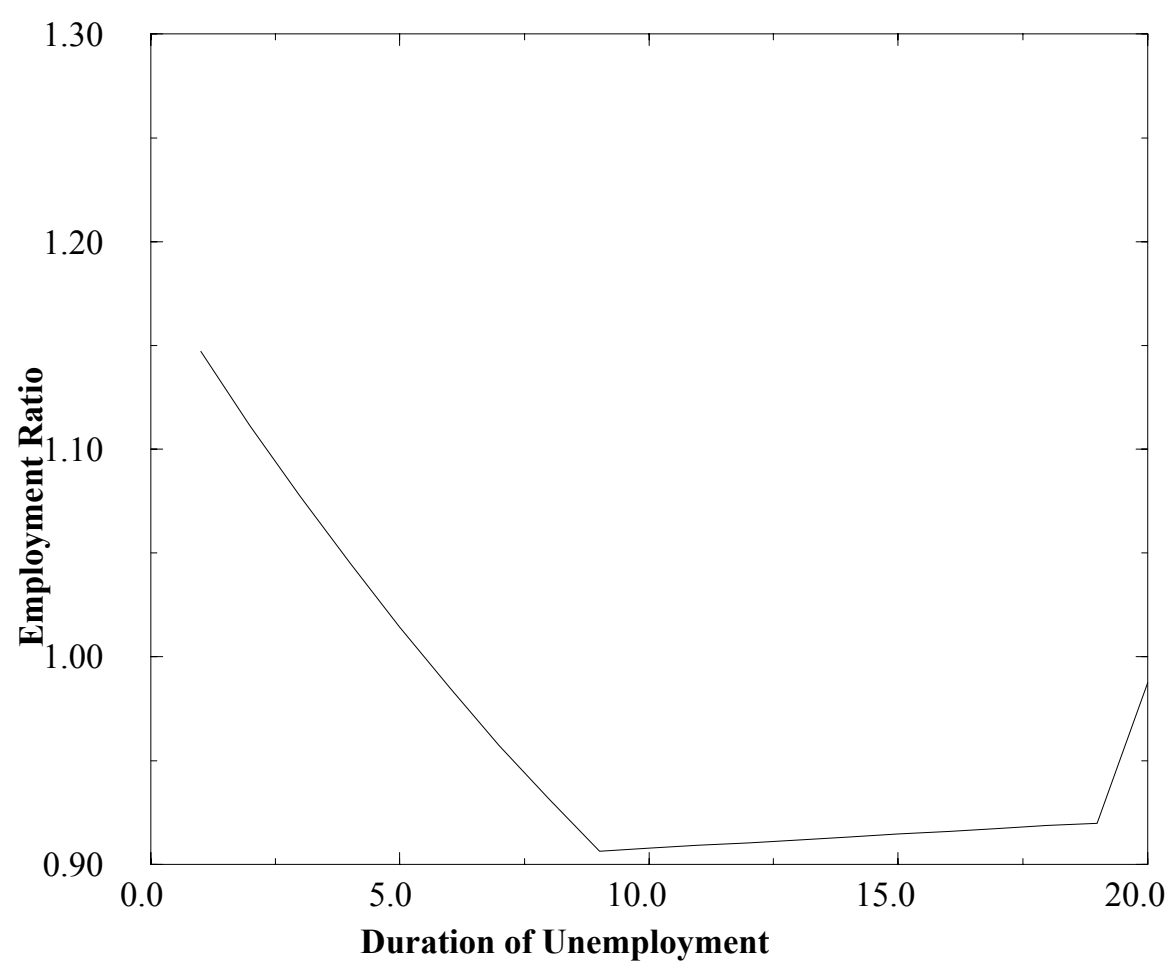

Figure 19. Change in unemployment at different durations with an unemployment voucher.

$$
\begin{aligned}
V(j, u)= & \frac{b_{j}^{-\frac{\alpha \gamma}{(1-\alpha) \gamma-1}}}{\gamma}\left(\frac{\beta a \theta_{j}}{1-\alpha}\right)[V(1, e)-V(j+1, u)]^{\frac{(1-\alpha) \gamma}{(1-\alpha) \gamma-1}} \\
& +\beta(1-d) V(j+1, u)+\beta[V(1, e)-V(j+1, u)] \cdot \theta_{j} \\
& (1-\alpha)\left(\frac{\beta a \theta_{j}}{1-\alpha}\right)^{\frac{1}{(1-\alpha) \gamma-1}}[V(1, e)-V(j+1, u)]^{\frac{1}{(1-\alpha) \gamma-1}} b_{j}^{-\frac{\alpha \gamma}{\left(1-\alpha\left(5^{1}\right)\right.}}
\end{aligned}
$$

for $j<J$. Collecting terms in the $V($.$) , Eq. (??) can be rewritten$ as: 
UNEMPLOYMENT VOUCHERS VERSUS LOW-WAGE SUBSIDIES

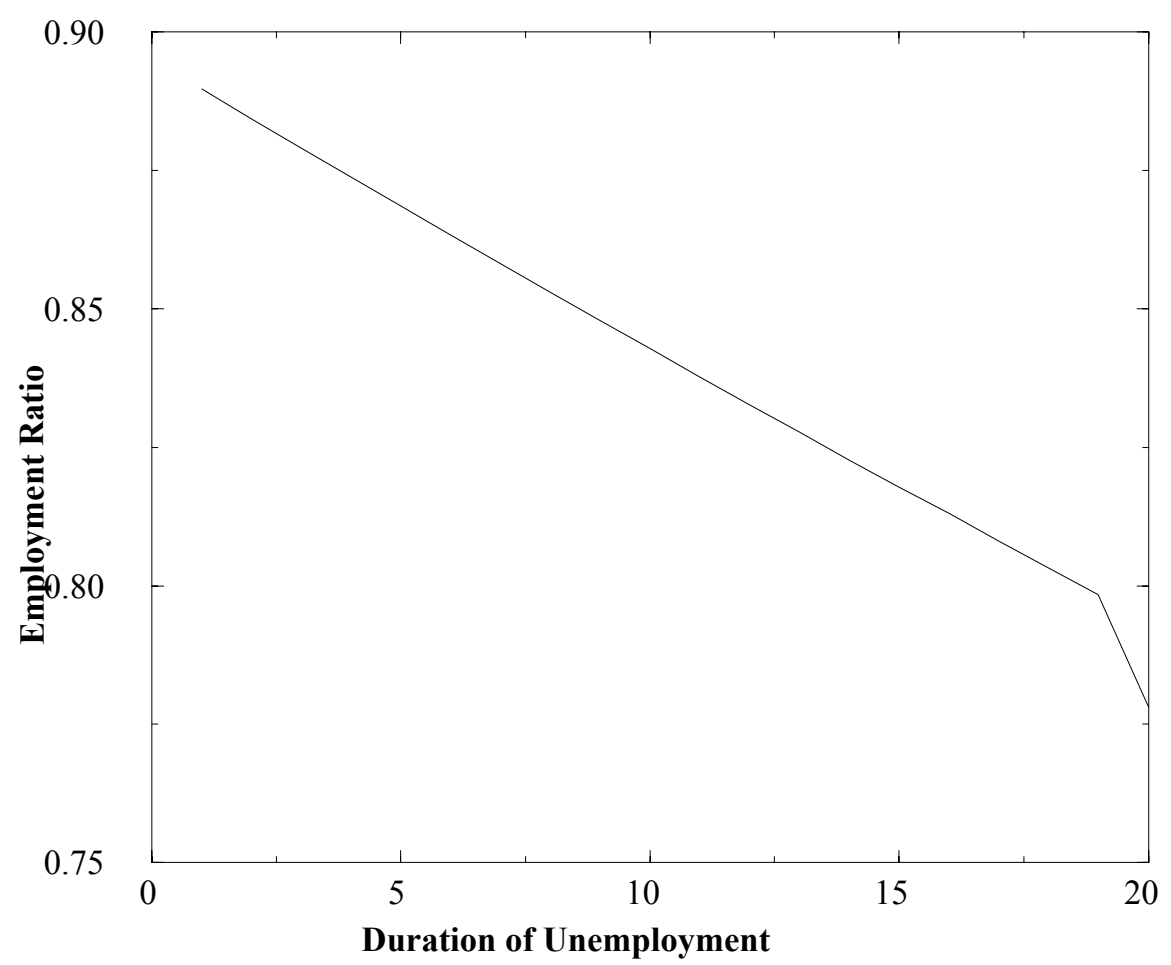

FiguRE 20. Ratio of unemployment with/without wage subsidy policy at different durations.

$$
\begin{aligned}
V(j, u)= & F_{0 j}[V(1, e)-V(j+1, u)]^{\frac{(1-\alpha) \gamma}{(1-\alpha) \gamma-1}}+F_{1 j} V(j+1,(u) 6) \\
& +F_{2 j}[V(1, e)-V(j+1, u)]
\end{aligned}
$$

where:

$$
\begin{gathered}
F_{0 j}=b_{j}^{\frac{-\alpha \gamma}{(1-\alpha) \gamma-1}}\left(\beta a \theta_{j}\right)^{\frac{(1-\alpha) \gamma}{(1-\alpha) \gamma-1}}\left[\frac{1}{1-\alpha}\right]^{\frac{1}{(1-\alpha) \gamma-1}}\left(\frac{1}{\gamma}\left[\frac{1}{1-\alpha}\right]-1\right) \\
F_{1 j}=\beta(1-d)
\end{gathered}
$$




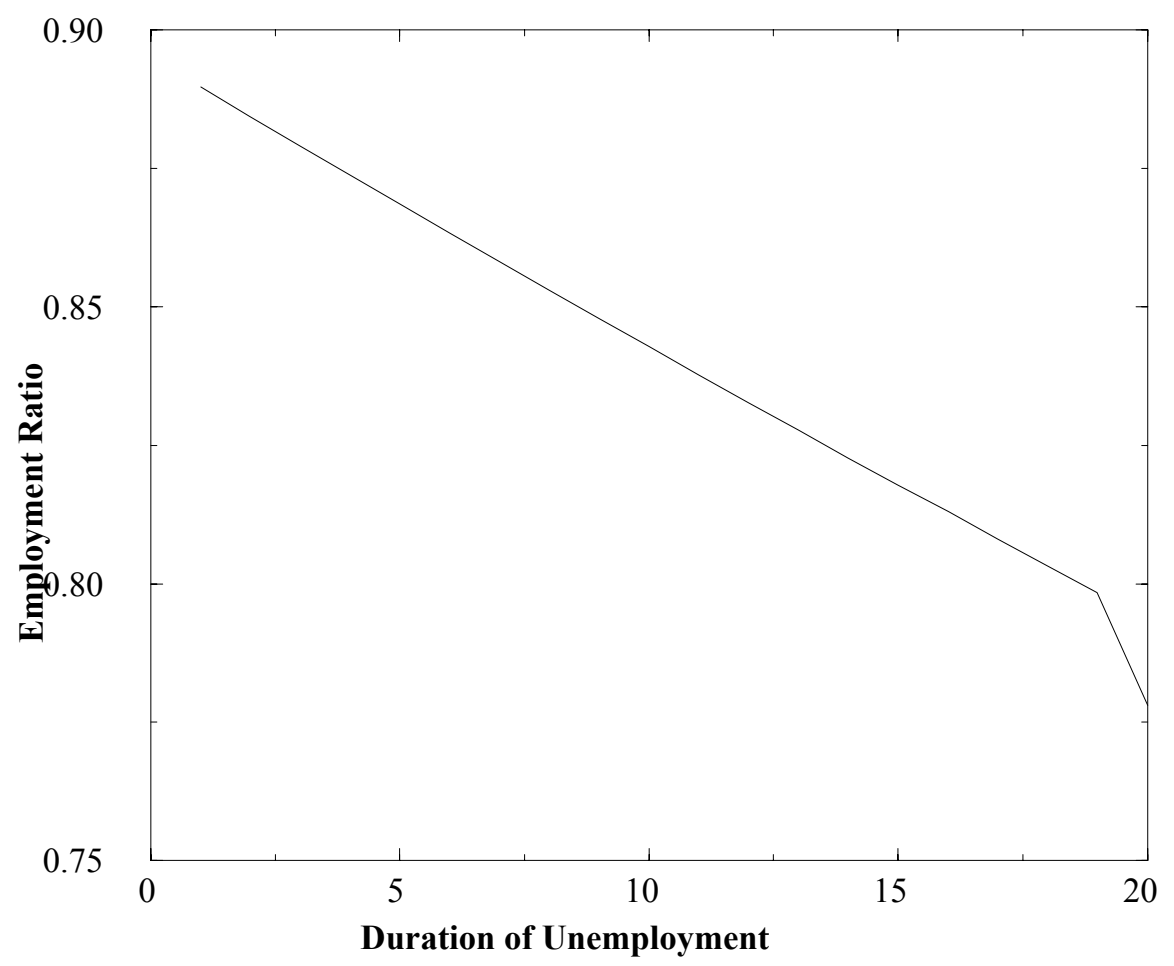

Figure 21. Change in employment at different durations with a wage subsidy.

$$
F_{2 j}=\beta \theta_{j}
$$

Similarly, for the employed:

$$
\begin{aligned}
V(i, e)= & \frac{\left(w_{i}^{*}\right)^{\frac{-\alpha \gamma}{(1-\alpha) \gamma-1}}}{\gamma}\left(\frac{\beta \phi_{j}}{1-\alpha}\right)^{\frac{(1-\alpha) \gamma}{(1-\alpha) \gamma-1}}[V(i+1, e)-V(1, u)]^{\left.\frac{(1-\alpha) \gamma}{(1-\alpha(2) \mathbb{1}}\right)} \\
& +\beta(1-d) V(i+1, e)-\left(\beta \phi_{j}\right)^{\frac{(1-\alpha) \gamma}{(1-\alpha) \gamma-1}} \cdot \\
& {[V(i+1, e)-V(1, u)]^{\frac{(1-\alpha) \gamma}{(1-\alpha) \gamma-1}}\left(\frac{1}{1-\alpha}\right)^{\frac{1}{(1-\alpha) \gamma-1}}\left(w_{i}^{*}\right)^{\frac{-\alpha \gamma}{(1-\alpha)(2 Z 3)}} }
\end{aligned}
$$


UNEMPLOYMENT VOUCHERS VERSUS LOW-WAGE SUBSIDIES

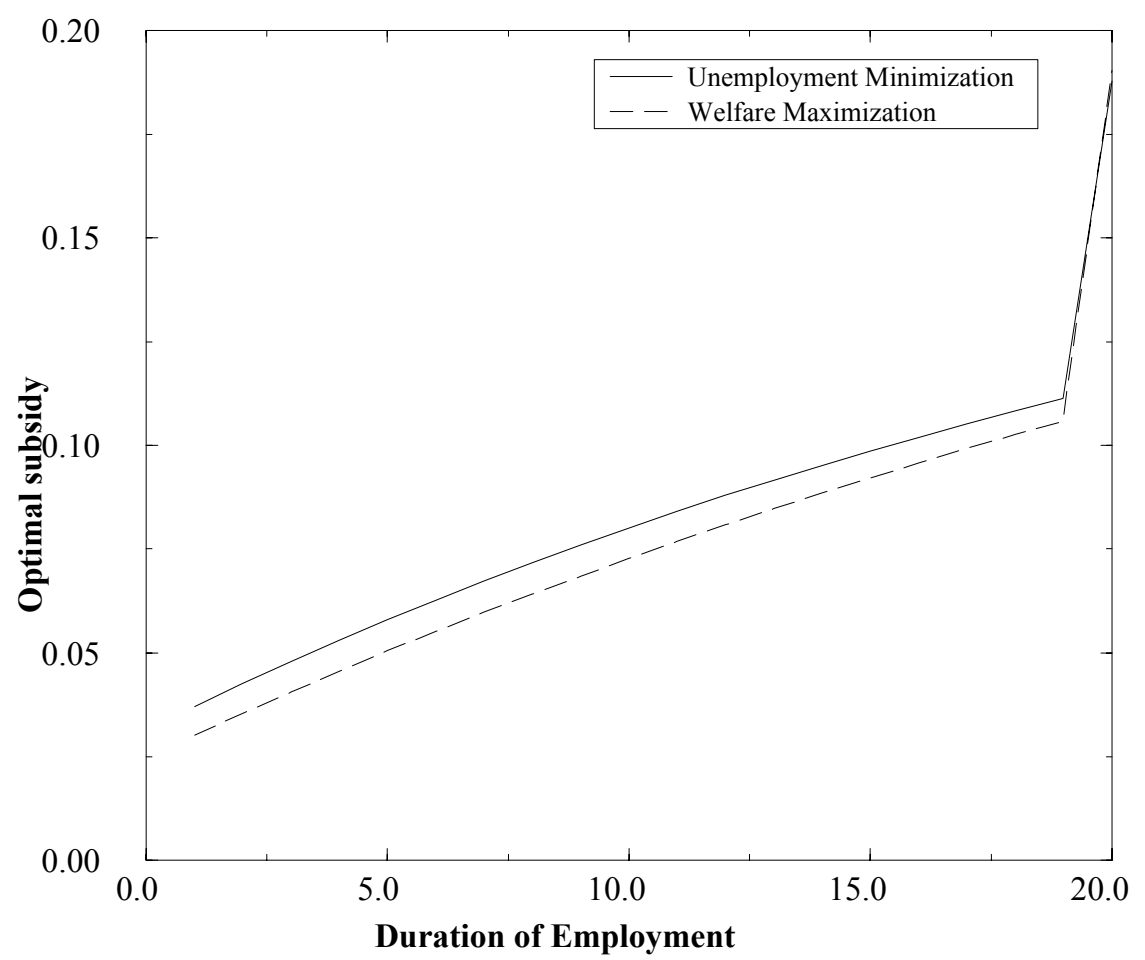

FiguRE 22. Optimal duration-dependent balancedbudget payroll policy with flat wages.

for $i<I$. As with Eq. (??), this can be rewritten in a manner similar to Eq. (??):

$$
V(i, e)=G_{0 i}[V(i+1, e)-V(1, u)]^{\frac{(1-\alpha) \gamma}{(1-\alpha) \gamma-1}}+G_{1 i} V(i+1, e)
$$

where:

$$
\begin{gathered}
G_{0 i}=\left(w_{i}^{*}\right)^{\frac{-\alpha \gamma}{(1-\alpha) \gamma-1}}\left(\phi_{i} \beta\right)^{\frac{(1-\alpha) \gamma}{(1-\alpha) \gamma-1}}\left[\frac{1}{1-\alpha}\right]^{\frac{1}{(1-\alpha) \gamma-1}}\left(\frac{1}{\gamma}\left[\frac{1}{1-\alpha}\right]-1\right) \\
G_{1 i}=\beta(1-d) .
\end{gathered}
$$




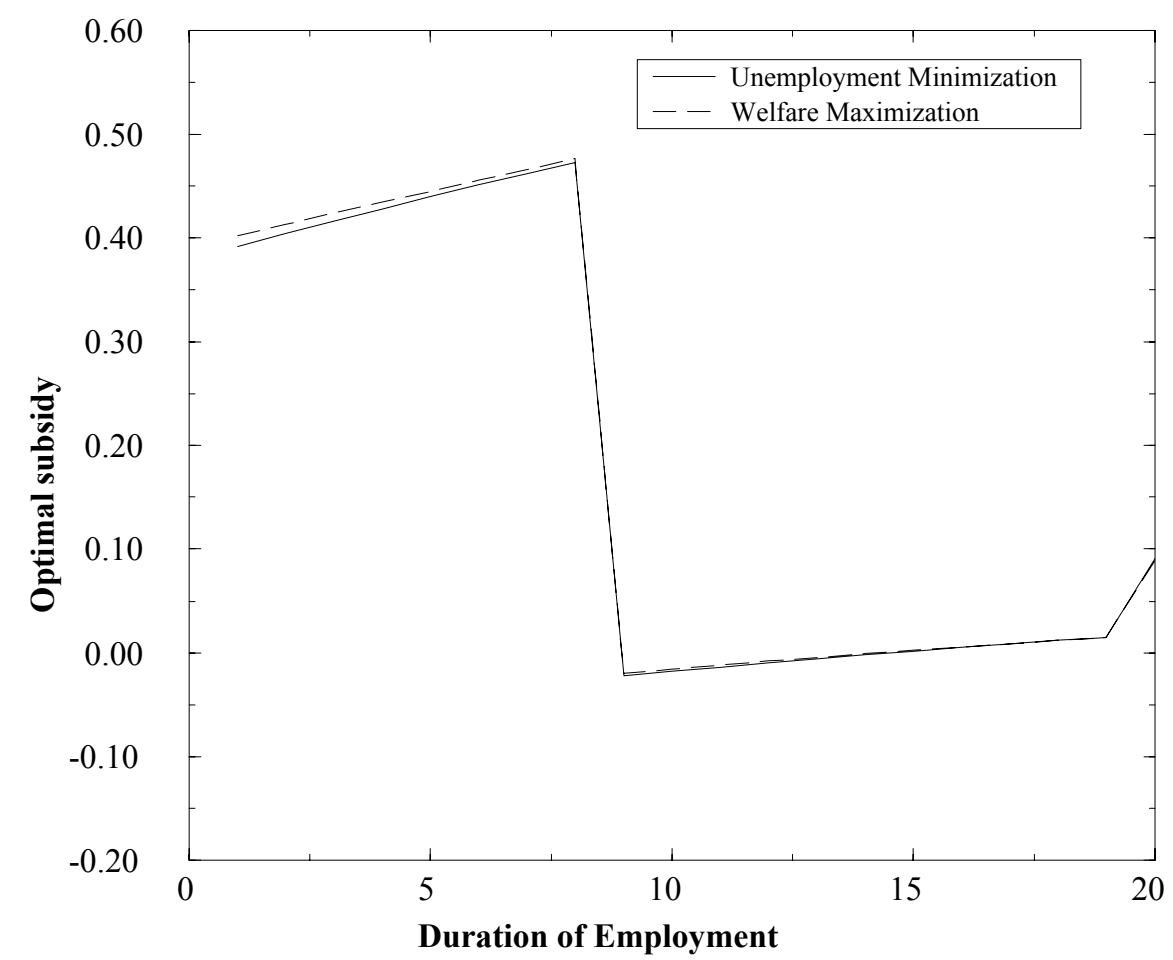

Figure 23. Optimal duration-dependent balancedbudget payroll policy with increasing wages.

For those unemployed for $J$ periods, the equation is:

$$
\begin{aligned}
V(J, u)= & F_{0 J}[V(1, e)-V(J, u)]^{\frac{(1-\alpha) \gamma}{(1-\alpha) \gamma-1}}+F_{1 J} V(J, u) \\
& +F_{2 J}[V(1, e)-V(J, u)]
\end{aligned}
$$

where:

$$
\begin{gathered}
F_{0 J}=b_{J}^{\frac{-\alpha \gamma}{(1-\alpha) \gamma-1}}\left(\beta a \theta_{J}\right)^{\frac{(1-\alpha) \gamma}{(1-\alpha) \gamma-1}}\left[\frac{1}{1-\alpha}\right]^{\frac{1}{(1-\alpha) \gamma-1}}\left(\frac{1}{\gamma}\left[\frac{1}{1-\alpha}\right]-1\right) \\
F_{1 J}=\beta(1-d)
\end{gathered}
$$




$$
F_{2 J}=\beta \theta_{J}
$$

For those employed for $I$ periods, the value function follows:

$$
V(I, e)=G_{0 I}[V(I, e)-V(1, u)]^{\frac{(1-\alpha) \gamma}{(1-\alpha) \gamma-1}}+G_{1 I} V(I, e)
$$

where:

$$
\begin{gathered}
G_{0 I}=\left(w_{I}^{*}\right)^{\frac{-\alpha \gamma}{(1-\alpha) \gamma-1}}\left(\phi_{I} \beta\right)^{\frac{(1-\alpha) \gamma}{(1-\alpha) \gamma-1}}\left[\frac{1}{1-\alpha}\right]^{\frac{1}{(1-\alpha) \gamma-1}}\left(\frac{1}{\gamma}\left[\frac{1}{1-\alpha}\right]-1\right) \\
G_{1 I}=\beta(1-d) .
\end{gathered}
$$

Eqs. (??),(24), (27) and (32) together form a $J+I$ system of nonlinear equations in $J+I$ unknowns.

\section{Constant Coefficients}

We will try to solve this system in one special case of constant parameters (e.g., $F_{0 j}=F_{0}, F_{1 j}=F_{1}, F_{2 j}=F_{2}, G_{0 i}=G_{0}, G_{1 i}=$ $\left.G_{1} \forall i, j\right)$. We define:

$$
\begin{aligned}
z & =\frac{(1-\alpha) \gamma}{(1-\alpha) \gamma-1} \\
\Delta_{i} V_{e} & =V(i, e)-V(1, u) \\
\Delta_{j} V_{u} & =V(1, e)-V(j, u)
\end{aligned}
$$

Now, consider the equation for those who have been employed for $I$ periods:

$$
\left(1-G_{1}\right) V(I, e)=G_{0}\left[\Delta_{I} V_{e}\right]^{z}
$$

so that:

$$
\Delta_{I} V_{e}=\left[\frac{\left(1-G_{1}\right)}{G_{0}} V(I, e)\right]^{\frac{1}{z}} .
$$

The individual employed $I-1$ periods solves:

$$
V(I-1, e)=G_{0}\left[\Delta_{I} V_{e}\right]^{z}+G_{1} V(I, e)
$$

Using Eq. (39, Eq. (40) becomes: 


$$
V(I-1, e)=G_{0}\left[\frac{\left(1-G_{1}\right)}{G_{0}} V(I, e)\right]+G_{1} V(I, e)=V(I, e)
$$

Since $V(I-1, e)=V(I, e), \Delta_{i-1} V_{e}=\Delta_{i} V_{e}$ and:

$$
V(I-2, e)=G_{0}\left[\frac{\left(1-G_{1}\right)}{G_{0}} V(I, e)\right]+G_{1} V(I-1, e)=V(I, e)
$$

Continuing this procedure, we find that $V(i, e)=V(I, e)$ for all $i$.

In a similar manner, we consider the equation for those who have been unemployed for $J$ periods:

$$
\left(1-F_{1}\right) V(J, u)=F_{0}\left[\Delta_{J} V_{u}\right]^{z}+F_{2} \Delta_{J} V_{u}
$$

Now, compare with the equation for those unemployed $J-1$ periods:

$$
V(J-1, u)=F_{0}\left[\Delta_{J} V_{u}\right]^{z}+F_{2} \Delta_{J} V_{u}+F_{1} V(J, u)
$$

Using Eq. (43), we have:

$$
V(J-1, u)=\left(1-F_{1}\right) V(J, u)+F_{1} V(J, u)=V(J, u) .
$$

To show that this continues to work:

$$
V(J-2, u)=F_{0}\left[\Delta_{J-1} V_{u}\right]^{z}+F_{2} \Delta_{J-1} V_{u}+F_{1} V(J-1, u)
$$

but since $V(J-1, u)=V(J, u), \Delta_{J-1} V_{u}=\Delta_{J} V_{u}$ and:

$$
V(J-2, u)=F_{0}\left[\Delta_{J} V_{u}\right]^{z}+F_{2} \Delta_{J} V_{u}+F_{1} V(J, u)
$$

which equals $V(J-1, u)$. We let $\bar{V}(u)=V(j, u)$ and $\bar{V}(e)=$ $V(i, e)$. We define:

$$
\Delta \bar{V}=\bar{V}(e)-\bar{V}(u)
$$

We have:

$$
\begin{gathered}
\left(1-F_{1}\right) \bar{V}(u)=F_{0}[\Delta \bar{V}]^{z}+F_{2} \Delta \bar{V} \\
\left(1-G_{1}\right) \bar{V}(e)=G_{0}[\Delta \bar{V}]^{z}
\end{gathered}
$$

We note from Eq. (49) and Eq. (50): 


$$
\begin{gathered}
\bar{V}(u)=\frac{F_{0}}{1-F_{1}}[\Delta \bar{V}]^{z}+\frac{F_{2}}{1-F_{1}} \Delta \bar{V} \\
\bar{V}(e)=\frac{G_{0}}{1-G_{1}}[\Delta \bar{V}]^{z}
\end{gathered}
$$

Subtracting Eq. (51) from Eq. (52), we obtain:

$$
\left(1+\frac{F_{2}}{1-F_{1}}\right) \Delta \bar{V}=\left[\frac{G_{0}}{1-G_{1}}-\frac{F_{0}}{1-F_{1}}\right][\Delta \bar{V}]^{z}
$$

so that if $\Delta \bar{V}$ is nonzero (which is true if $\bar{V}(u)$ is bounded):

$$
\left(1+\frac{F_{2}}{1-F_{1}}\right)=\left[\frac{G_{0}}{1-G_{1}}-\frac{F_{0}}{1-F_{1}}\right][\Delta \bar{V}]^{z-1}
$$

and: ${ }^{21}$

$$
\Delta \bar{V}=\left[\frac{\left(1+\frac{F_{2}}{1-F_{1}}\right)}{\left[\frac{G_{0}}{1-G_{1}}-\frac{F_{0}}{1-F_{1}}\right]}\right]^{\frac{1}{z-1}}
$$

From Eq. (52), we obtain:

$$
\begin{aligned}
\bar{V}(e)= & {\left[\frac{\left(1+\frac{F_{2}}{1-F_{1}}\right)}{\left[\frac{G_{0}}{1-G_{1}}-\frac{F_{0}}{1-F_{1}}\right]}\right]^{\frac{z}{z-1}} \frac{G_{0}}{1-G_{1}} } \\
& \bar{V}(u)=\bar{V}(e)-\Delta \bar{V} .
\end{aligned}
$$

The case of non-constant coefficients is, in general, analytically intractable. However, one useful point comes from examining the model with only two types of employed (e.g., $I=2)$. We again by considering the equation for those who have been employed for 2 periods or more (e.g., insiders):

Hence:

$$
\left(1-G_{1}\right) V(2, e)=G_{02}\left[\Delta_{2} V_{e}\right]^{z}
$$

${ }^{21}$ We note from Eq. (35) that:

implying boundedness.

$$
z-1=\frac{1}{(1-\alpha) \gamma-1}<0,
$$




$$
\Delta_{2} V_{e}=\left[\frac{\left(1-G_{1}\right)}{G_{02}} V(2, e)\right]^{\frac{1}{z}}
$$

The entrant employed 1 periods solves:

$$
V(1, e)=\left[G_{0,1}\left[\frac{\left(1-G_{1}\right)}{G_{0,2}}\right]+G_{1}\right] V(2, e)
$$

so that the relationship between $V(1, e)$ and $V(2, e)$ depends on whether $G_{0,2}$ is smaller or larger than $G_{0,1}$. We note from Eq. (25) that $G_{0, i}$ is increasing in the wage; hence, if wages for entrants are lower and all else is equal, $G_{0,1}<G_{0,2}$ and the value for being an insider is higher.

\section{Appendix B: The Fraction of Long Term Unemployed}

This appendix derives the fraction of long term unemployed in a Markov model with constant transition rates. The difference equations for unemployment:

$$
v_{t, x}=(1-h) v_{t-1, x-1}
$$

have the solution $v_{t, x}=(1-h)^{x} v_{t-x, 0}$ for $t>x$ where the term $v_{t-x, 0}$ is the number of entrants to unemployment $x$ periods ago. The total number of unemployed $v_{x}^{s}$ of duration $x$ in steady state is:

$$
\sum_{x=0}^{\infty}(1-h)^{x} v_{0}^{s}=\frac{v_{0}^{s}}{h}
$$

where $v_{0}^{s}$ is the number of entrants to unemployment (and the superscript $s$ denotes the steady state).

The number unemployed for duration greater than or equal to $y$ is: 


$$
\begin{aligned}
\sum_{x=y}^{\infty}(1-h)^{x} v_{0}^{s} & =v_{0}^{s} \sum_{x=0}^{\infty}(1-h)^{x+y} \\
& =v_{0}^{s}(1-h)^{y} \sum_{x=0}^{\infty}(1-h)^{x} \\
& =\frac{v_{0}^{s}(1-h)^{y}}{h}
\end{aligned}
$$

The ratio of Eq. (C.2) to Eq. (C.1) is $(1-h)^{y}$. This calculation assumes duration-independent transition rates and a steady state.

\section{Appendix C: Computational Solutions}

We recall that a worker employed for $I$ periods solves:

$$
\begin{aligned}
V(I, e) & =\max _{l_{I e}}\left[u\left(w_{I}^{*}, l_{I e}\right)\right. \\
& \left.+\beta\left(f_{I}\left(l_{I e}\right) V(1, u)+\left(1-f_{I}\left(l_{I e}\right)-d\right) V(I, e)\right)\right]
\end{aligned}
$$

If we fix a value of $V(I, e)-V(1, u)$ we then can solve for $V(I, e)$. Having solved for $V(I, e)$ we then can solve for $V(I-1, e)$ using Eq. (2). We proceed recursively in this manner until we have solved for $V(1, e)$.

An individual who is unemployed for $J$ periods solves:

$V(J, u)=\max _{l_{J u}}\left[u\left(b_{J}, l_{J u}\right)+\beta\left[h_{J}\left(l_{J u}\right) V(1, e)+\left(1-h_{1}\left(l_{1 u}\right)-d\right) V(J, u)\right]\right]$

which, given a fixed value for $V(1, e)-V(J, u)$, can be solved for $V(J, u)$. We then solve for $V(J-1, u)$ until reaching $V(1, u)$. If the solutions for $V(1, e)-V(J, u)$ and $V(I, e)-V(1, u)$ and differ from our guess, we adjust our guess for these differences using numerical derivatives. Once the adjustments have all been made, we are left with the correct solution.

Regarding the calculation of the steady state employment and unemployment rates, recall that the states of the model evolve according to:

$$
\mathbf{S}_{t}=\mathbf{T S}_{t-1}
$$


where $\mathbf{T}$ is given by Eq. (??). In steady states, $\mathbf{S}_{t}=\mathbf{S}_{t-1}$, so:

$$
(\mathbf{T}-\mathbf{I}) \bar{S}=0
$$

where $\bar{S}$ is the steady state level of employment and unemployment at different durations. Eq. (63) involves solving for the eigenvector $\bar{S}$ associated with the eigenvalue 1 of $\mathbf{T}$.. We know at least one such eigenvalue exists because the columns of $\mathbf{T}$ sum to 1 ; in fact, for non-zero hiring and firing probabilities, the matrix is non-decomposable so that there is only one eigenvalue of 1 ((Stewart 1993), p. 29). Eq. (63) could be solved using an eigenvalue solver.

\section{Appendix D: Microfoundations of the Hiring and Separation FunCtions}

This appendix provides illustrative microfoundations for the hiring and separation activities described in general terms above. The hiring and separation activities are influenced by the behavior of both the workers and the firms. We focus on the workers' influence in this example.

To motivate the hire rate, we consider that workers going to interviews at a firm face a hire rate of $\omega_{j}$ which is known to the workers. Workers have a time endowment of 1 when unemployed and obtaining an interview takes $c$ units of time. Workers who do one interview are hired with a probability $\omega_{j}$; if they are not hired (with probability $1-\omega_{j}$ ), they may proceed to a second interview and be hired with a probability $\omega_{j}$. The probability $\omega_{j}$ is determined by the firm's profit-maximizing behavior, described later.

Thus each worker's hiring rate (the total probability of being hired) is

$$
h_{j}=\omega_{j} \sum_{k=0}^{N-1}\left(1-\omega_{j}\right)^{k}=1-\left(1-\omega_{j}\right)^{N}
$$

This hiring rate may now be expressed in terms of the unemployed worker's leisure. The worker's total time endowment (to be split between leisure and job search) is 1 , and $N$ interviews take $\delta N$ units of time, where $\delta$ is a positive constant. Thus, leisure when unemployed is $1-\delta N$ so that $N=\frac{1-l_{j u}}{\delta}$. Hence 


$$
h_{j}\left(l_{j u}\right)=1-\left(1-\omega_{j}\right)^{\frac{1-l_{j u}}{\delta}}
$$

which is decreasing in the leisure when unemployed. A linear approximation to Eq. (65) is:

$$
h_{j}\left(l_{j u}\right)=1+\log \left(1-\omega_{j}\right) \frac{\left(l_{j u}-1\right)}{\delta}
$$

which can be rewritten as:

$$
h_{j}\left(l_{j u}\right)=\theta_{j}\left(1-a l_{j u}\right) .
$$

We shall use this linear hiring function in the ensuing analysis.

Next, consider a simple, illustrative way to motivate the firing rate. Suppose that output per worker is given by the production function $q_{i}=\frac{\epsilon}{l_{i e}}$, where $\epsilon$ is a random variable uniformly distributed between 0 and $\alpha$ (a positive constant), iid across workers. Let the firm have a threshold level of output $\bar{q}_{i}$ below which it fires the employee and above which it retains him. This threshold level is determined in the firm's profit maximization problem, considered later. Then firing rate (probability of firing a worker) is $f=\left(\bar{q} l_{i e} / \alpha\right)$. Thus the firing rate can be expressed simply as

where $\phi_{i}=\bar{q} / \alpha .^{22}$.

$$
f_{i}\left(l_{i e}\right)=\phi_{i} l_{i e}
$$

\section{REFERENCES}

Burgess, S., And H. Rees (December 1994): "Lifetime Tenure and Transient Jobs: Job Tenure in Britain 1975-1991," CEPR Discussion Paper 1098.

Hoon, H. T., And E. S. Phelps (1992): "Macroeconomic

Shocks in a Dynamized Model of the Natural Rate of

Unemployment," American Economic Review, 82, 889-900.

(1997): "Payroll Taxes and VAT in a Labor-Turnover

Model of the Natural Rate," International Tax and Public

Finance, 41, 185-201.

\footnotetext{
${ }^{22}$ Another way of justifying Eq. (5) is as a technological relationship between monitoring of workers and separations. Alternatively, it may be justified in terms of a quitting model such as in (Phelps 1994) (Hoon and Phelps 1992); workers who wish to quit supply little effort and it is for the firm to raise the wage in order to induce them to supply more labor.
} 
Institute for Employment Studies (1994): "Evaluation of Workstart Pilots," Discussion paper, London.

Layard, R., S. Nickell, and R. Jackman (1991):

Unemployment: Macroeconomic Performance and the Labour Market. Oxford University Press.

Martin Hanblin Research (1996): "A Report on Workstart," Discussion paper, London.

Millard, S., and D. Mortensen (1997): "The Unemployment and Welfare Effects of Labour Market Policy," in Unemployment Policy: Government Options for the Labour Market, pp. 545-572. Cambridge.

Mortensen, D., And C. Pissarides (1994): "Job Creation and Job Destruction in a Theory of Unemployment," Review of Economic Studies, 66, 397-415.

(NERA), N. E. R. A. (1995): "OECD Wage Subsidy Evaluation," Discussion paper, London. London.

OrszaG, J. M., and D. Snower (1997): "From Unemployment Benefits to Unemployment Support Accounts," Paper presented at the conference, Rethinking the Welfare Society, La Coruna, Spain.

(1998): "A Continuum Model of Employment and Unemployment: An Overview," in Contemporary Economic Development Revisited: Macroeconomic Policy and Financial Systems. Macmillan.

— (1999): "Youth Unemployment and Government Policy," Journal of Population Economis, 12(2).

- (2000): "A Macro Theory of Employment Vouchers," German Economic Review, 1(4), 385 - 419.

Phelps, E. (1994): Structural Slumps: The Modern Equilibrium Theory of Unemployment, Interest and Assets. Harvard. (1996): "Wage Subsidy Programmes: Alternative Designs," in Unemployment Policy: Government Options for the Labour Market, ed. by G. de la Deheza, and D. Snower. Cambridge University Press.

Phelps, E. S. (1997): Rewarding Work:How to Restore Participation and Self-Support to Free Enterprise. Harvard University Press. 
Snower, D. (1994): "Converting Unemployment Benefits into Employment Subsidies," American Economic Review Papers and Proceedings, pp. 65-70.

(1996): "The Simple Economics of Benefit Transfers," in Unemployment Policy: Government Options for the Labour Market, ed. by G. de la Deheza, and D. Snower. Cambridge University Press.

Stewart, W. J. (1993): Introduction to the Numerical Solution of Markov Chains. Princeton University Press.

Woodbury, S., and R. Spiegelman (1987): "Bonuses to workers and employers to reduce unemployment: randomized trials in Illinois," American Economic Review, 77, 513-30.

Watson Wyatt, Reigate, Surrey, RH2 9PQ U.K.

E-mail address: Michael.Orszag@eu. watsonwyatt.com

Department of Economics, Birkbeck College, Univ. of London, LONDON W1P 2LL U.K; CEPR AND IZA.

E-mail address: dsnower@econ.bbk.ac.uk 


\section{IZA Discussion Papers}

\begin{tabular}{|c|c|c|c|c|}
\hline No. & Author(s) & Title & Area & Date \\
\hline 520 & U. Sunde & $\begin{array}{l}\text { Unobserved Bilateral Search on the Labor } \\
\text { Market: A Theory-Based Correction for a } \\
\text { Common Flaw in Empirical Matching Studies }\end{array}$ & 1 & $06 / 02$ \\
\hline 521 & $\begin{array}{l}\text { U. Sunde } \\
\text { R. Fahr }\end{array}$ & $\begin{array}{l}\text { Employment Status, Endogenous Regional } \\
\text { Mobility, and Spatial Dependencies in Labor } \\
\text { Markets }\end{array}$ & 1 & 06/02 \\
\hline 522 & $\begin{array}{l}\text { S.-Å. Dahl } \\
\varnothing . \text { A. Nilsen } \\
\text { K. Vaage }\end{array}$ & $\begin{array}{l}\text { Gender Differences in Early Retirement } \\
\text { Behaviour }\end{array}$ & 3 & $06 / 02$ \\
\hline 523 & $\begin{array}{l}\text { J. Falkinger } \\
\text { V. Grossmann }\end{array}$ & $\begin{array}{l}\text { Workplaces in the Primary Economy and Wage } \\
\text { Pressure in the Secondary Labor Market }\end{array}$ & 3 & $07 / 02$ \\
\hline 524 & $\begin{array}{l}\text { J. J. Dolado } \\
\text { F. Felgueroso } \\
\text { J. F. Jimeno }\end{array}$ & $\begin{array}{l}\text { Recent Trends in Occupational Segregation by } \\
\text { Gender: A Look Across the Atlantic }\end{array}$ & 2 & $07 / 02$ \\
\hline 525 & $\begin{array}{l}\text { J. J. Heckman } \\
\text { C. Heinrich } \\
\text { J. Smith }\end{array}$ & The Performance of Performance Standards & 6 & $07 / 02$ \\
\hline 526 & $\begin{array}{l}\text { E. Leuven } \\
\text { H. Oosterbeek }\end{array}$ & $\begin{array}{l}\text { A New Approach to Estimate the Wage Returns } \\
\text { to Work-Related Training }\end{array}$ & 6 & $07 / 02$ \\
\hline 527 & J. C. van Ours & The Locking-in Effect of Subsidized Jobs & 4 & $07 / 02$ \\
\hline 528 & $\begin{array}{l}\text { P. Manzini } \\
\text { M. Mariotti }\end{array}$ & $\begin{array}{l}\text { Arbitration and Mediation: An Economic } \\
\text { Perspective }\end{array}$ & 3 & $07 / 02$ \\
\hline 529 & $\begin{array}{l}\text { J. M. Orszag } \\
\text { D. Snower }\end{array}$ & Incapacity Benefits and Employment Policy & 3 & $07 / 02$ \\
\hline 530 & $\begin{array}{l}\text { M. Karanassou } \\
\text { D. Snower }\end{array}$ & Unemployment Invariance & 3 & $07 / 02$ \\
\hline 531 & $\begin{array}{l}\text { M. Karanassou } \\
\text { H. Sala } \\
\text { D. Snower }\end{array}$ & $\begin{array}{l}\text { Unemployment in the European Union: A } \\
\text { Dynamic Reappraisal }\end{array}$ & 3 & $07 / 02$ \\
\hline 532 & $\begin{array}{l}\text { J. M. Orszag } \\
\text { D. Snower }\end{array}$ & $\begin{array}{l}\text { From Unemployment Benefits to Unemployment } \\
\text { Accounts }\end{array}$ & 3 & $07 / 02$ \\
\hline 533 & $\begin{array}{l}\text { S. Fölster } \\
\text { R. Gidehag } \\
\text { M. Orszag } \\
\text { D. Snower }\end{array}$ & $\begin{array}{l}\text { From Unemployment Benefits to Unemployment } \\
\text { Accounts }\end{array}$ & 3 & $07 / 02$ \\
\hline 534 & $\begin{array}{l}\text { A. Lindbeck } \\
\text { D. Snower }\end{array}$ & The Insider-Outsider Theory: A Survey & 3 & $07 / 02$ \\
\hline 535 & $\begin{array}{l}\text { P. Manzini } \\
\text { D. Snower }\end{array}$ & $\begin{array}{l}\text { Wage Determination and the Sources of } \\
\text { Bargaining Power }\end{array}$ & 3 & $07 / 02$ \\
\hline 536 & $\begin{array}{l}\text { M. Orszag } \\
\text { D. Snower }\end{array}$ & Pension Taxes versus Early Retirement Rights & 3 & $07 / 02$ \\
\hline 537 & $\begin{array}{l}\text { M. Orszag } \\
\text { D. Snower }\end{array}$ & $\begin{array}{l}\text { Unemployment Vouchers versus Low-Wage } \\
\text { Subsidies }\end{array}$ & 3 & $07 / 02$ \\
\hline
\end{tabular}

An updated list of IZA Discussion Papers is available on the center's homepage www.iza.org. 